\title{
Concept Feasibility Report for Using Co-Extrusion to Bond Metals to Complex Shapes of U-10Mo
}

CA Lavender DM Paxton

MT Smith
A Soulami

VV Joshi

DE Burkes

December 2013

Pacific Northwest

NATIONAL LABORATORY

Proudly Operated by Battelle Since 1965 


\title{
DISCLAIMER
}

This report was prepared as an account of work sponsored by an agency of the United States Government. Neither the United States Government nor any agency thereof, nor Battelle Memorial Institute, nor any of their employees, makes any warranty, express or implied, or assumes any legal liability or responsibility for the accuracy, completeness, or usefulness of any information, apparatus, product, or process disclosed, or represents that its use would not infringe privately owned rights. Reference herein to any specific commercial product, process, or service by trade name, trademark, manufacturer, or otherwise does not necessarily constitute or imply its endorsement, recommendation, or favoring by the United States Government or any agency thereof, or Battelle Memorial Institute. The views and opinions of authors expressed herein do not necessarily state or reflect those of the United States Government or any agency thereof.

\author{
PACIFIC NORTHWEST NATIONAL LABORATORY \\ operated by \\ BATTELLE \\ for the \\ UNITED STATES DEPARTMENT OF ENERGY \\ under Contract DE-AC05-76RL01830 \\ Printed in the United States of America \\ Available to DOE and DOE contractors from the \\ Office of Scientific and Technical Information, \\ P.O. Box 62, Oak Ridge, TN 37831-0062; \\ ph: (865) 576-8401 \\ fax: $(865)$ 576-5728 \\ email: reports@adonis.osti.gov \\ Available to the public from the National Technical Information Service \\ 5301 Shawnee Rd., Alexandria, VA 22312 \\ ph: (800) 553-NTIS (6847) \\ email: orders@ntis.gov <http://www.ntis.gov/about/form.aspx> \\ Online ordering: http://www.ntis.gov
}

से This document was printed on recycled paper.

(82010) 


\title{
Concept Feasibility Report for Using Co-Extrusion to Bond Metals to Complex Shapes of U-10Mo
}

\author{
CA Lavender \\ A Soulami \\ DM Paxton \\ VV Joshi \\ MT Smith \\ DE Burkes
}

December 2013

Prepared for

the U.S. Department of Energy

under Contract DE-AC05-76RL01830

Pacific Northwest National Laboratory

Richland, Washington 99352 



\begin{abstract}
In support of the Convert Program of the U.S. Department of Energy's National Nuclear Security Administration (DOE/NNSA) Global Threat Reduction Initiative (GTRI), Pacific Northwest National Laboratory (PNNL) has been investigating manufacturing processes for the uranium-10\% molybdenum (U-10Mo) alloy plate fuel for the U.S. high-performance research reactors (USHPRR). This report documents the results of PNNL's efforts to develop the extrusion process for this concept. The approach to the development of a co-extruded complex-shaped fuel has been described and an extrusion of DU10Mo was made. The initial findings suggest that given the extrusion forces required for processing U$10 \mathrm{Mo}$, the co-extrusion process can meet the production demands of the USHPRR fuel and may be a viable production method. The development activity is in the early stages and has just begun to identify technical challenges to address details such as dimensional tolerances and shape control. New extrusion dies and roll groove profiles have been developed and will be assessed by extrusion and rolling of U10Mo during the next fiscal year. Progress on the development and demonstration of the co-extrusion process for flat and shaped fuel is reported in this document.
\end{abstract}





\section{Acronyms and Abbreviations}

304SS

AA6061

BSE

DOE

DU

EDS

FY

GTRI

HFIR

SEM

U-Mo

$\mathrm{U}-10 \mathrm{Mo}$

USHPRR
304 stainless steel

Aluminum Association Alloy 6061

backscattered electron

U.S. Department of Energy

depleted uranium

energy dispersive x-ray spectroscopy

fiscal year

Global Threat Reduction Initiative

High Flux Isotope Reactor

scanning electron microscopy

uranium-molybdenum

uranium-10\% molybdenum

U.S. High-Performance Research Reactor 



\section{Contents}

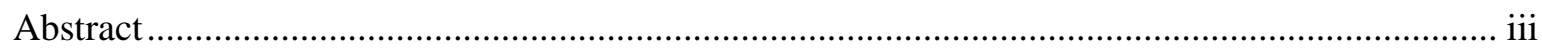

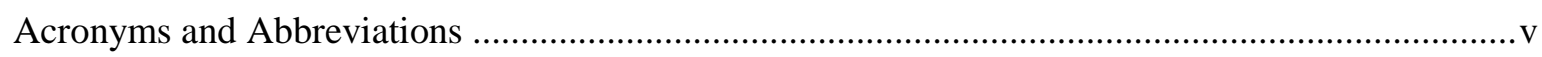

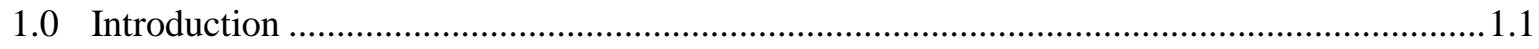

2.0 Conceptual Co-Extruded Complex Shaped U-10Mo GTRI Fuel Process.............................2.1

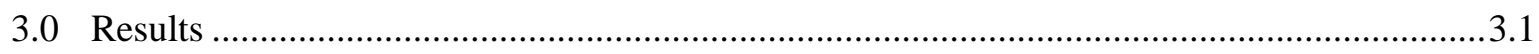

3.1 U-Mo Extrusion System Development Summary …..................................................... 3.1

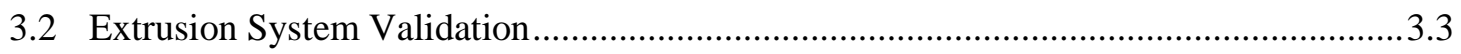

3.3 Development of the Canned Extrusion Process .............................................................. 3.5

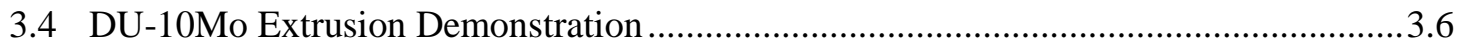

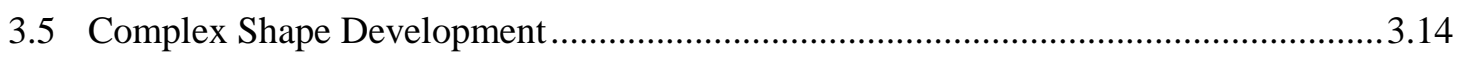

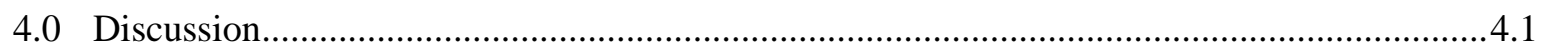

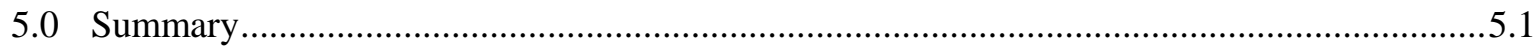

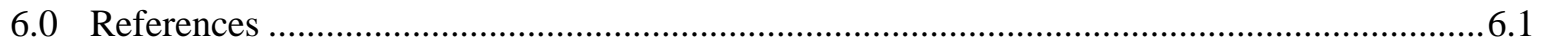




\section{Figures}

1.1 Nominal As-Bonded Geometry of the USHPRR U-10Mo Fuel Prior to Final Shaping .........1.1

1.2 Schematic of the Co-extruded Alpha-Uranium Zirconium-Clad Fuel used in N-Reactor........1.2

2.1 Optical Micrograph of the Cross-Section of a Co-Extruded U-Si Alloy with Zirconium

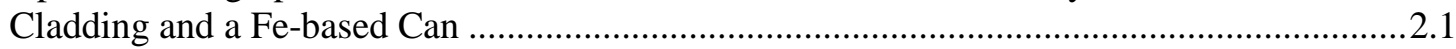

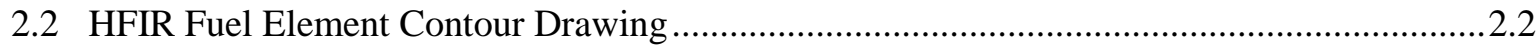

2.3 Co-Extruded Round and Elliptical Shapes to be Hot/Cold Rolled to the Final HFIR Shape ..2.2

2.4 Schematic Representation of Rolling a Co-Extruded Shape to the Final HFIR Profile ..........2.3

3.1 Major Components of the Extrusion Press Developed for U-Mo Co-Extrusion ......................3.2

3.2 PNNL Extrusion System Installed in a Radiologically Controlled Area................................3.3

3.3 Extrusion Surface Finishes on AA6061 using Dag and Filled Grease Lubricants ..................3.4

3.4 Load and Displacement Curves for AA6061 Extruded with Filled-Grease and Dag Lubricants

3.5 Cross-Section of the Extruded 304SS and Cu-Based Alloy Can .......................................... 3.5

3.6 Force versus Displacement Curve for the Extrusion of 304 Stainless, Canned and Uncanned.3.6

3.7 DU-10Mo Casting from Which the Extrusion Billets were Machined...................................3.7

3.8 Cu-based Alloy Can and U-10Mo Billet Prior to Assembly and Extrusion .............................. 3.8

3.9 DU-10Mo Extrusion Cooling in the Runout Tray after Extrusion ......................................... 3.8

3.10 Force-Displacement Diagram for the U-10Mo Extrusion and Stainless Steel Showing a Relatively High Upset Force Followed by a Relatively Constant Running Force ..................3.9

3.11 Backscattered SEM Image of the Transverse Section of the Middle Region of the As-Cast Billets.

3.12 EDS Map of the As-Cast Sample Indicating the Presence of Silicon and Molybdenum in the Script Regions and Uranium and Carbon in the Plate/Needle Regions.....

3.13 Macro-Images of the Extruded DU-10Mo Rod

3.14 Low Magnification BSE-SEM Montage of the Tip of an Extrusion along the Longitudinal Direction of the Extrusion.

3.15 High Magnification BSE-SEM Images of the Region of Microstructure Showing the Effect of the Extrusion Strain on the Particle Fracture

3.16 Elemental EDS Map of the As-Extruded Intermetallics and Carbides

3.17 Low Magnification BSE-SEM Images of the Extrusion at the Middle and Tail of the Sample along the Extrusion Direction

3.18 The DU-10Mo Extrusion and the Peeled-Off Can Showing the Rough Surfaces

3.19 Roll Groove Profiles for the Roll Pockets Needed to Roll a Complex Shaped Extrusion to the HFIR Profile Using a Reduction Ratio of 3:1.

3.20 Streamlined Extrusion Die for the Shaped Co-Extrusion to be Rolled to the HFIR Profile..3.16

3.21 Engineered Drawings of the Roll Pockets for Rolling the Shaped Extrusion to the HFIR Profile 


\section{Table}

3.1 Nominal As-Cast Chemistry for the Casting from Which the Extrusion Billets were Machined...... 


\subsection{Introduction}

In support of the Convert Program of the U.S. Department of Energy's National Nuclear Security Administration (DOE/NNSA) Global Threat Reduction Initiative (GTRI), Pacific Northwest National Laboratory (PNNL) has been investigating manufacturing processes for the uranium-10\% molybdenum (U-10Mo) alloy plate fuel. The U-10Mo made with low-enriched uranium (LEU) has been identified as the most promising alternative to the current highly enriched uranium used in the United States' fleet of high-performance research reactors (USHPRR) (1). The nominal configuration of the new LEU U-10Mo plate fuel, shown in Figure 1.1, comprises a U-10Mo fuel foil enriched to slightly less than 20\% U-235, a thin $\mathrm{Zr}$ interlayer-diffusion barrier and a relatively thick cladding of 6061 aluminum (2). This new configuration will require the use of processes and materials not currently in use, and as such, the Convert Program is investigating several alternative approaches in order to rapidly determine the most costeffective and robust method for manufacturing the plate fuel. This report details the progress on the alternative manufacturing process called co-extrusion.

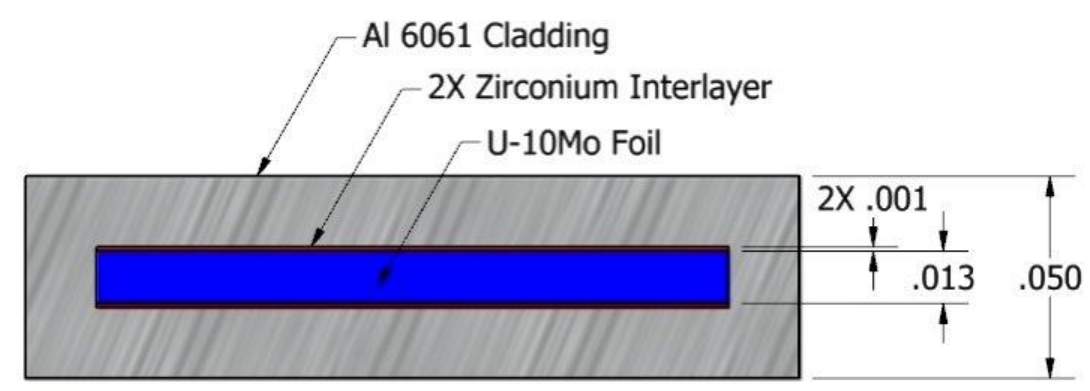

Figure 1.1. Nominal As-Bonded Geometry of the USHPRR U-10Mo Fuel Prior to Final Shaping

Co-extrusion was used for many years in the DOE complex, particularly at the Hanford site, to produce metallic uranium fuels (3). The fuels were typically alpha uranium metal clad by co-extrusion with zirconium. The last reactor using metallic fuel at Hanford was the N-Reactor, which used an alpha uranium annular fuel (a tube within a tube) as shown in Figure 1.2 (4). 


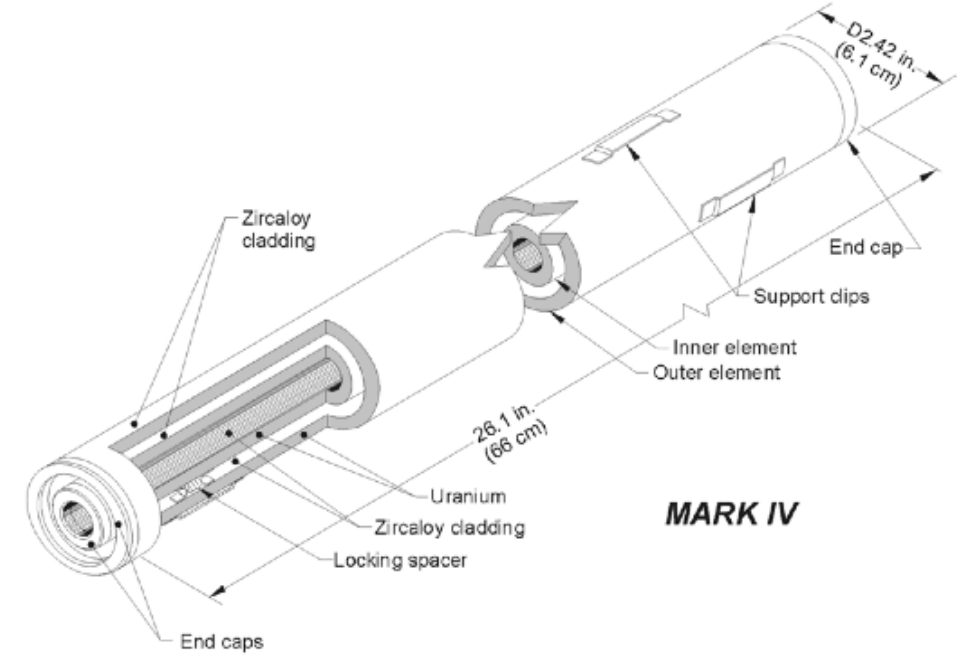

Figure 1.2. Schematic of the Co-extruded Alpha-Uranium Zirconium-Clad Fuel used in N-Reactor

Co-extrusion allows for a high-pressure and high-strain bonding process that results in a very high quality metallurgical bond. There are many forms of co-extrusion; however, for reactive, high-strength metals like zirconium and uranium in configurations that require tight dimensional control, the typical process uses a machined uranium billet sleeved with zirconium and encapsulated with an outer can (5). The outer can is normally evacuated and sealed to prevent ingress of air during preheat and extrusion. The co-extrusion approach to be developed for the U-10Mo fuel will follow the zirconium-sleeve/outer-can process used for N-Reactor fuels (6). This process will prevent air contamination of the interface between $\mathrm{Zr}$ and U-10Mo and the machined U-10Mo billet will have the accurate dimensional control needed for the USHPRR fuels. The approach to this process will be detailed in this report.

The performance of a USHPRR fuel is substantially different from that required for the weapons reactors that used the alpha phase of uranium. For the USHPRR, the uranium gamma phase, stabilized by 10 weight percent molybdenum, will be required. This Mo addition extends the time for the equilibrium for the deleterious transformation to alpha and gamma prime $\left(\mathrm{U}_{2} \mathrm{Mo}\right)$ to a long enough time to allow the metallic fuel to be used in the USHPRRs (7). The addition of Mo to the uranium has been reported to result in an order of magnitude increase in elevated temperature strength of the U-10Mo (8). The increase in strength requires that the U-10Mo be extruded at higher temperatures under higher forces than are required for alpha uranium.

Coincident with the GTRI co-extrusion development there has been activity at PNNL for the DOE Office of Nuclear Energy Fuel Cycle Research and Development (FCRD) program to develop a U-7Mo-X annular fuel (9). These coincident development activities have enabled leveraging of the projects to reestablish the extrusion capability with the versatility to meet both project needs. The FCRD project will extrude a tube using lower forces than are required for the complex shaped $\mathrm{Zr}$-clad extrusion needed for the GTRI fuel. An extrusion system and a billet canning line were built to accommodate both projects. Progress in development, demonstration and validation of the extrusion system will be detailed in this report. 


\subsection{Conceptual Co-Extruded Complex Shaped U-10Mo GTRI Fuel Process}

\section{Past metallic uranium nuclear fuels were normally tubular like the example Zr-clad uranium- (U-Si) fuel shown in}

Figure 2.1 (prior to removal of the can). In this example, the uranium is the dark layer; it is clad on the on the outside by a zirconium layer, which in turn is covered by a thin layer of the Fe-based can. For the USHPRR, the extrusion would be solid.

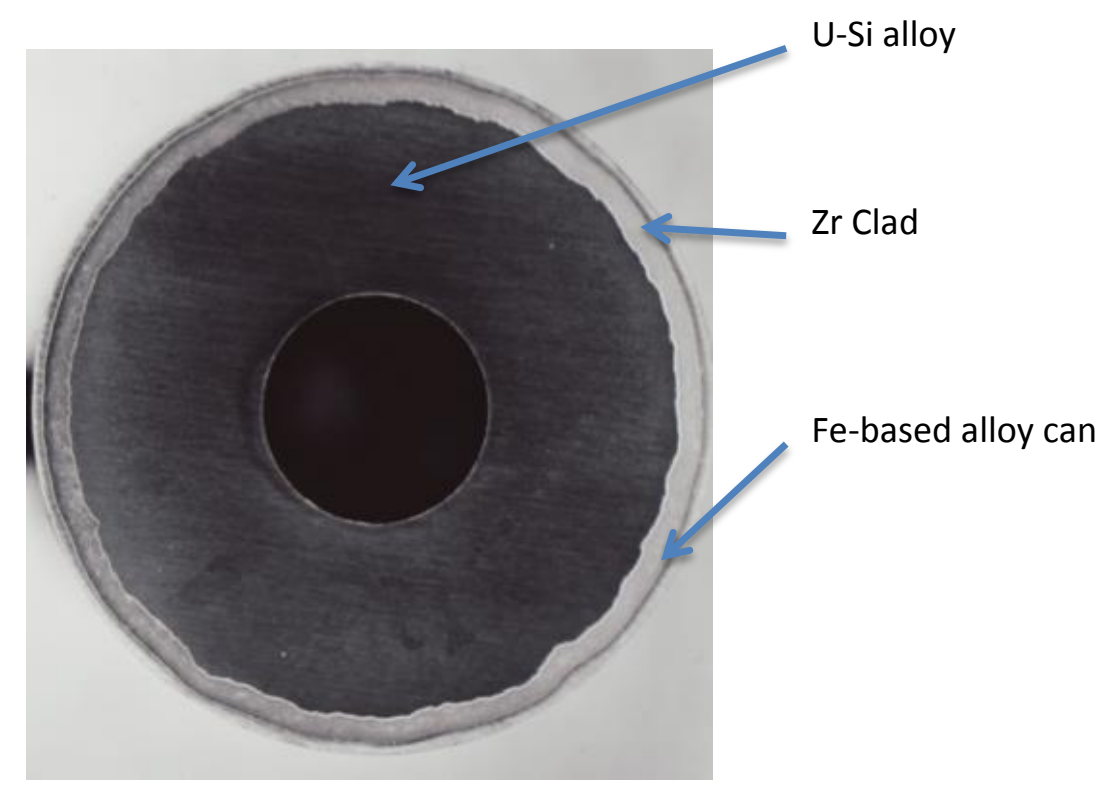

Figure 2.1. Optical Micrograph of the Cross-Section of a Co-Extruded U-Si Alloy with Zirconium Cladding and a Fe-based Can

The GTRI fuel is a substantially different configuration from that extruded previously for weapons reactors. The GTRI fuel has the nominal configuration shown in Figure 1.2, where the uranium fuel is clad with a thin interlayer of $\mathrm{Zr}$ called a diffusion barrier, which is clad with aluminum. The fuel configurations for the USHPRR vary for each reactor and depending on location within the fuel bundle normally require a final shaping by stamping. This configuration lends itself to a canned co-rolling process, which is the current baseline process. However, the High Flux Isotope Reactor (HFIR), which accounts for $40 \%$ of the annual fuel need, uses an "airfoil" shape shown in Figure 2.2 for the outer element fuel plates (10). 


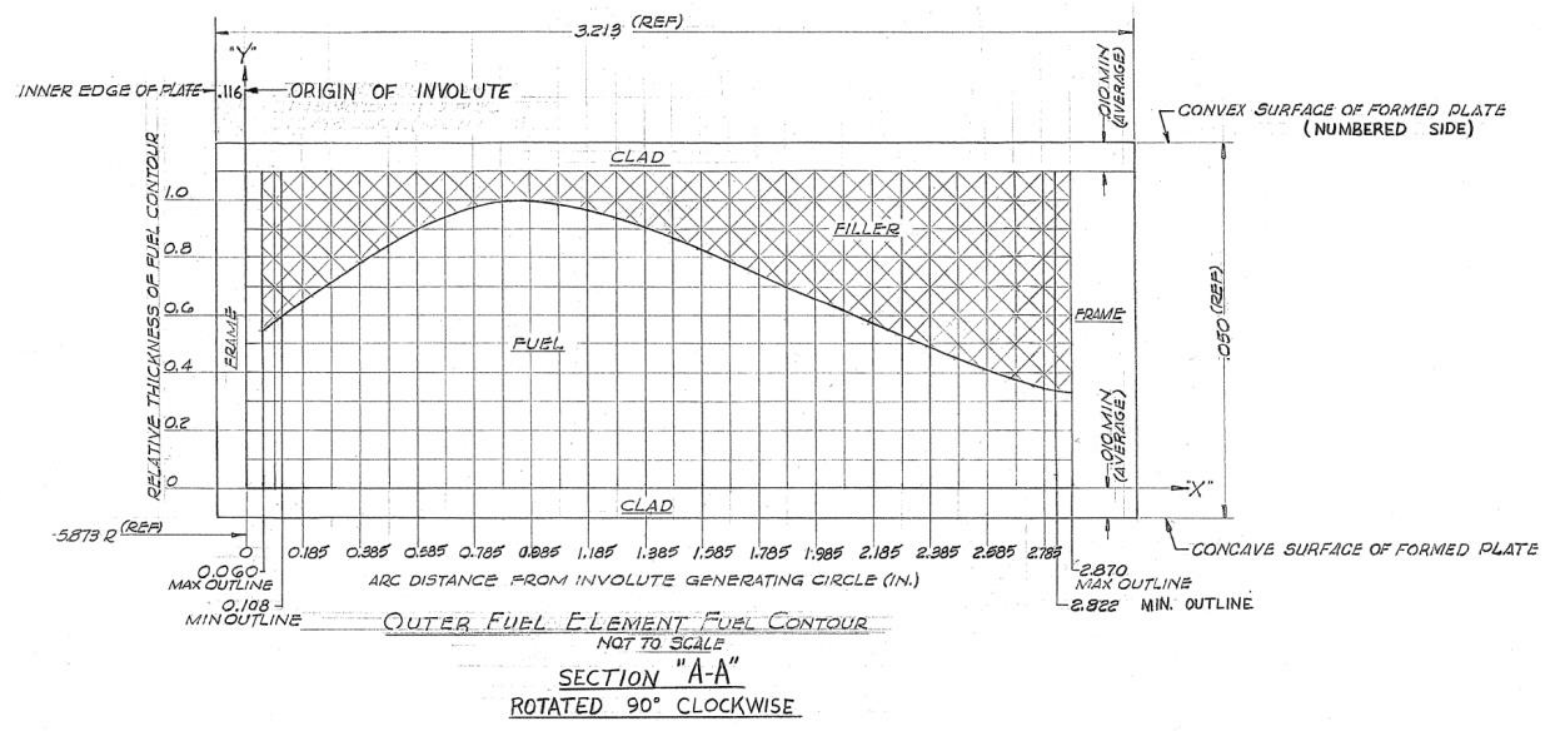

Figure 2.2. HFIR Outer Fuel Element Fuel Contour Drawing

This HFIR "airfoil" fuel contour presents a unique challenge from a fabrication standpoint and complicates the bonding of $\mathrm{Zr}$ to $\mathrm{U}-10 \mathrm{Mo}$ when using the proposed canned co-rolling process. An alternative to the picture-frame-pack-rolling process is co-extrusion combined with shape rolling. In this process, the $\mathrm{Zr}$ will be bonded to the $\mathrm{U}-10 \mathrm{Mo}$ during hot co-extrusion to produce a rod or elliptical shape such as shown in Figure 2.3. This co-extruded shape will then be rolled to the HFIR profile using a roll mill equipped with grooved rolls to produce the final desired shape as shown by the schematic in Figure 2.4. The rolling step is needed for two purposes: 1) to make sure that the billet is processed to the final fuel length and 2) to make sure that the dimensional shape and tolerances are met. Hot extrusion tolerances are typically on the order of $+/-0.1 \mathrm{~mm}$ and the drawing requirements of the HFIR fuel are closer to $+/-0.01 \mathrm{~mm}$. The final shape and dimensional tolerances will be achieved by the high precision in cold rolling.

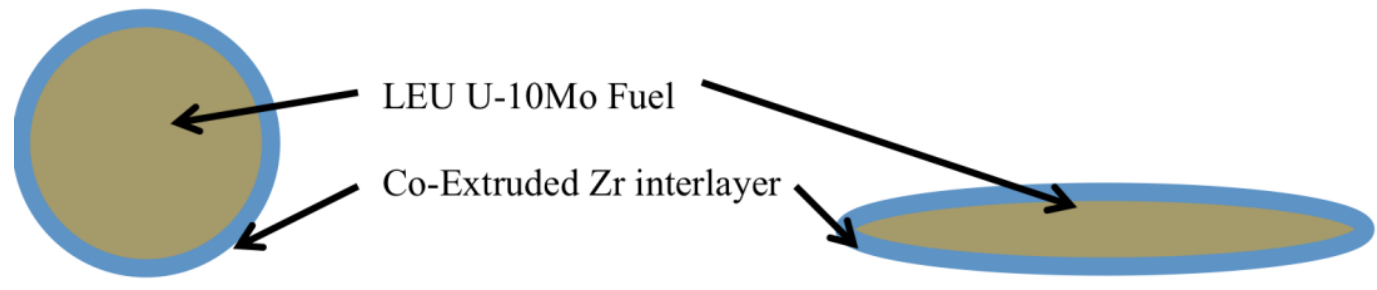

Figure 2.3. Co-Extruded Round (left) and Elliptical (right) Shapes to be Hot/Cold Rolled to the Final HFIR Shape 


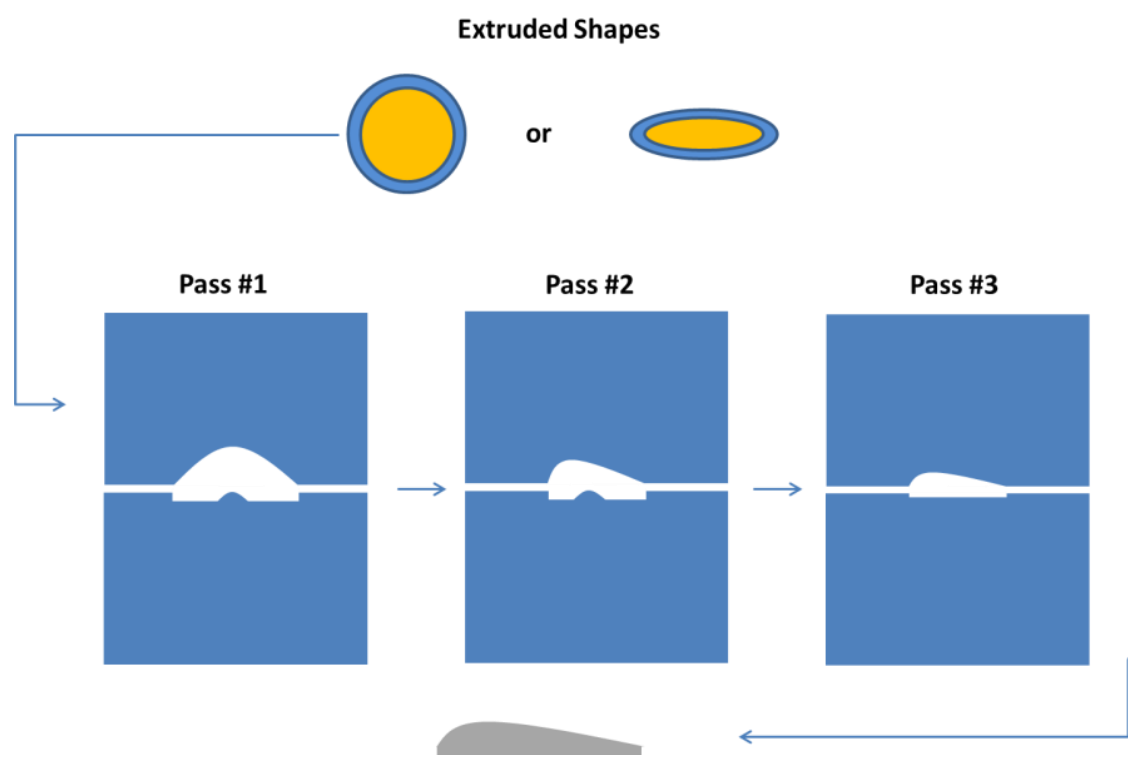

Figure 2.4. Schematic Representation of Rolling a Co-Extruded Shape to the Final HFIR Fuel Profile

Ideally, the outer can will be made from a material that can be chemically removed without attacking the zirconium sleeve. For this process step the outer can material will be $\mathrm{Cu}$ - or $\mathrm{Fe}$-based, allowing the use of nitric or sulfuric acid for can removal.

The proposed major process steps to produce a complex co-extruded fuel shape are the following:

1. Cast a right cylinder of U-10Mo.

2. Homogenize to produce uniform Mo distribution.

3. Turn the outside diameter to true the diameter and clean the surface for bonding.

4. Sleeve the billet in $\mathrm{Zr}$ tubing.

5. Can in a $\mathrm{Fe}-$ or $\mathrm{Cu}$-based can.

6. Evacuate the can using a pigtail and crimp seal or electron beam welding system.

7. Hot extrude.

8. Pickle to remove can.

9. Hot/cold roll to final shape.

10. Hot isostatic bond aluminum cladding.

11. Machine to plate configuration.

12. Follow normal HFIR fuel processing steps. 


\subsection{Results}

\subsection{U-Mo Extrusion System Development Summary}

The design objectives of the extrusion development task were to develop an extrusion press system capable of direct extrusion of billets having elevated high-temperature flow stress. Included in this category are the family of materials that are considered "difficult to extrude" such as stainless steels, titanium, steels, and uranium (5). In order to develop a commercially feasible USHPRR fuel design and production process it is necessary to demonstrate the ability to extrude a cast uranium-molybdenum (U-Mo) ingot into a smaller rod or shape for cold rolling into a shaped product form. Although some extrusion of alpha phase uranium fuels has been done on a large scale in the past (3), very limited capability currently exists within industry or the DOE laboratory complex for the extrusion of uranium.

The design of the PNNL extrusion press system focused on being able to extrude U-Mo billets of less than 1.0 inch in diameter using extrusion reduction ratios of between 3 and 16. This would enable PNNL to produce a rod or elliptical product of suitable size for testing in the Advanced Test Reactor (ATR) at Idaho National Laboratory. Extrusion temperatures of up to $900^{\circ} \mathrm{C}$ were used as the basis for tooling material selection and operational requirements. Development of a bench-top extrusion system that is designed around small diameter billets presents a number of technical challenges. Large commercial extrusion presses process large-diameter metal billets having large thermal mass. In contrast, the PNNL bench-top extrusion press system must be able to extrude at high temperatures small billets that have low thermal mass and high surface area, both of which can lead to excessive temperature drop and contribute to high friction. Key requirements of the process to overcome these challenges are the use of heated tooling, a rapid billet loading process, and the selection of suitable high temperature lubricants.

During the course of FY12 and into FY13 the extrusion development task focused on a series of six subtasks listed below. For brevity, more-detailed information on Subtasks 1 through 4 can be found in PNNL-22730. ${ }^{1}$

1. Extrusion Equipment Design and Stress Analysis

2. Detailed Mechanical Design and Tooling Fabrication

3. Control System Development

4. Assembly and Functional Testing

5. Operational Development and Validation

6. Development of the Canned Extrusion Process

Forces required to extrude the "difficult to extrude" materials such as stainless steel and uranium alloys are typically quite high. The project generated a finite element model for the main components of the system and the resulting stress analysis was used to size and design the major extrusion system components. For direct extrusion, the limiting stresses occur in the stem (which is the approximate diameter of the inside of the container liner). The use of high quality hot working steels (such as $\mathrm{H}-13$ and H-21) provides a safe working stress of approximately 190,000 psi. This stress limit then determines the

\footnotetext{
${ }^{1}$ Bennett WD et al. 2013. FY-13 Status Report for the U-Mo Concept. PNNL-22730, Pacific Northwest National
} Laboratory, Richland, Washington. 
size of the hydraulic ram and the design of the container. For the container, a three-part shrink fit design provides for higher safe working pressures by introducing compressive stresses between each of the cylinders, which acts to keep stress levels for the heated container temperature $\left(450^{\circ} \mathrm{C}\right)$ at safe working levels. A schematic of the key features is given in Figure 3.1.

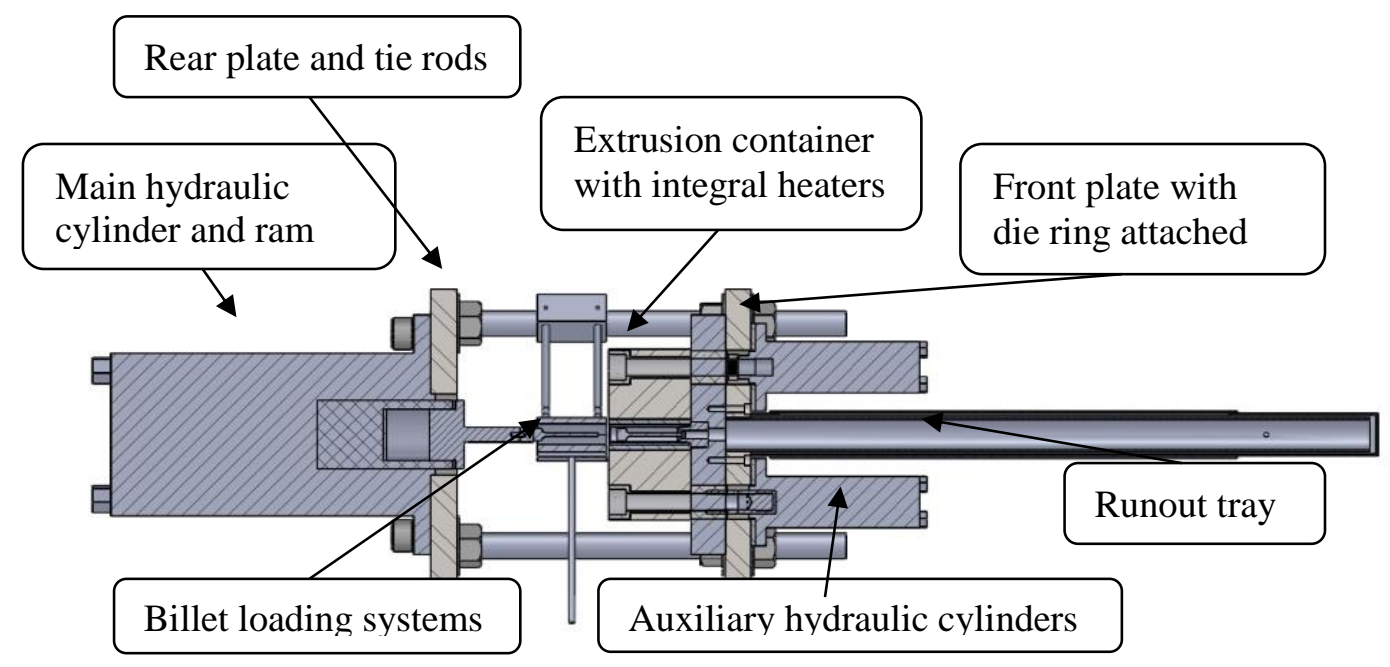

Figure 3.1. Major Components of the Extrusion Press Developed for U-Mo Co-Extrusion

During FY13 a small-scale extrusion facility was designed and constructed and the extrusion press was set up in a radiologically controlled area to begin extrusion of depleted uranium (DU)-10Mo billets. The configuration of the complete bench-top extrusion press with supporting furnace and billet loading system is shown in Figure 3.2 as installed in the radiologically controlled area. The PNNL system can be summarized as follows: it has a variable and programmable ram speed, controllable tooling temperatures up to $450^{\circ} \mathrm{C}$, and a versatile die stack that allows conical, streamline, bridge, and shear die extrusion. The extrusions can be tubular, shaped or rods and are not limited in length. Length is limited by the billet flow stress that limits extrusion ratio and maximum ram stroke of approximately 12 " with 6 " of daylight. Billet preheat is carried out in resistance furnaces and is limited to a maximum of $1100^{\circ} \mathrm{C}$. Higher temperatures would require different heating systems. Maximum extrusion force is 75 tons and maximum ram speed is 45 inches per minute. 


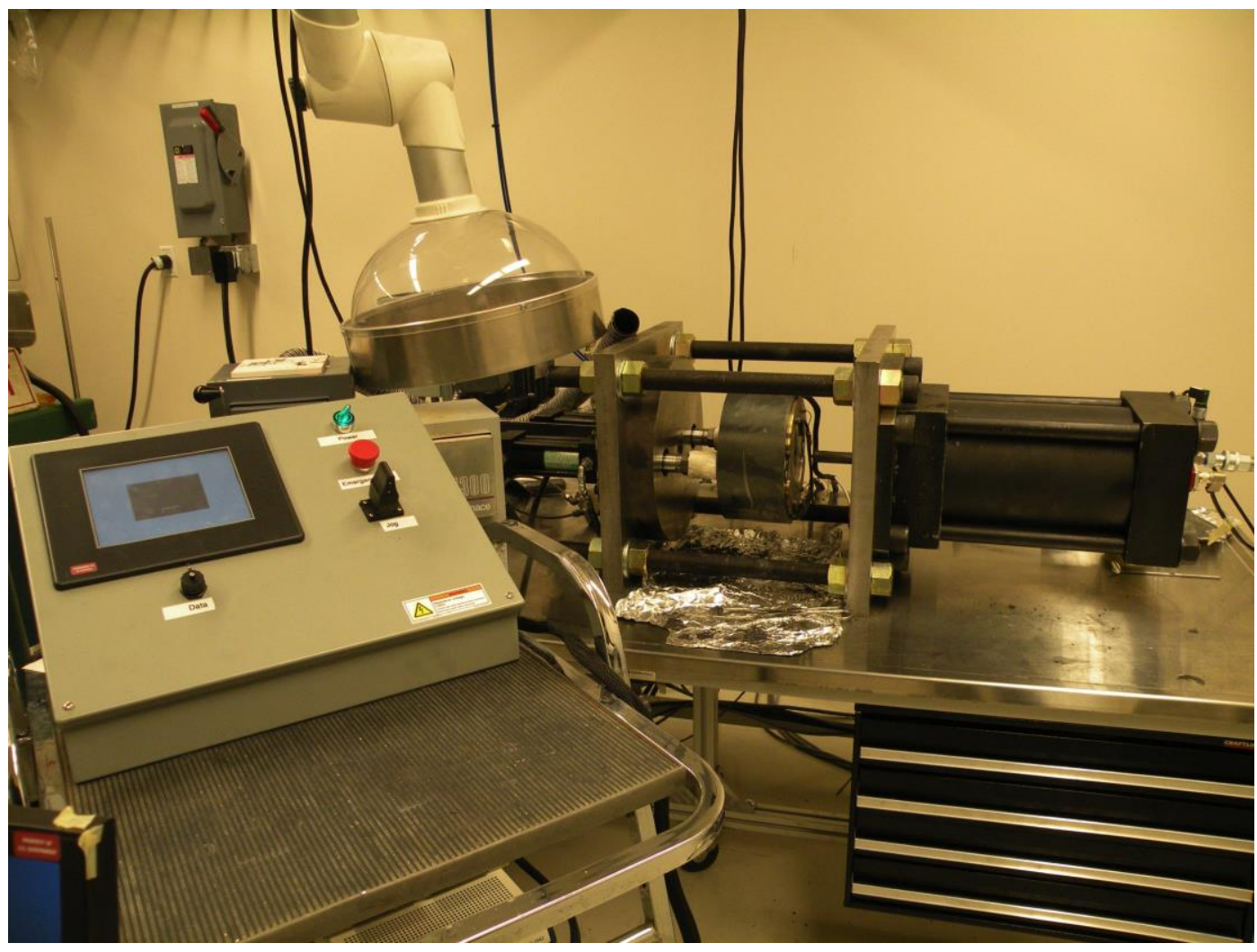

Figure 3.2. PNNL Extrusion System Installed in a Radiologically Controlled Area. The control system is shown in the left foreground and the press and snorkel are in the background.

\subsection{Extrusion System Validation}

A series of extrusions were performed using aluminum alloy 6061 (AA6061) and 304 stainless steel (304SS) (to act as U-10Mo surrogate) billets. Initially trials were performed using AA6061, which is considered an easy-to-extrude alloy and is typically extruded at moderate extrusion speeds and temperatures up to the range of $500^{\circ} \mathrm{C}$. During these trials, the sequence for loading the billet and ancillary tooling was developed and transfer times of less than 4 seconds were achieved.

A very low friction viscous lube process called the Ugine Séjournet process (5) was attempted using glass-based lubricants for the surrogate 304SS. The Ugine Séjournet process can produce the lowest extrusion forces due to low redundant work and friction; however, the low thermal mass of the small billet size led to excessive thickening of the glass and ultimately bonding of the billet to the cooler tooling (5). As a result, the decision was made to not use the glass lubricants. Filled grease lubricants capable of use at higher temperatures (up to $800^{\circ} \mathrm{C}$ ) were then evaluated, starting with extrusions of AA6061. Application of the grease lubricant to the inside of the container and the face of the die, combined with coating of the billet with graphite resulted in significant reduction in extrusion load and superior surface finish. A comparison of the surface finishes of an AA6061 extrusion using the graphite/Dag lubricant and the extrusion using the high-temperature grease lubricant is shown in Figure 3.3. The load/displacement curves for the two lubricant conditions are shown in Figure 3.4 that shows the high-temperature filledgrease lubricant reduced the extrusion load for AA6061 by approximately 50 percent. 


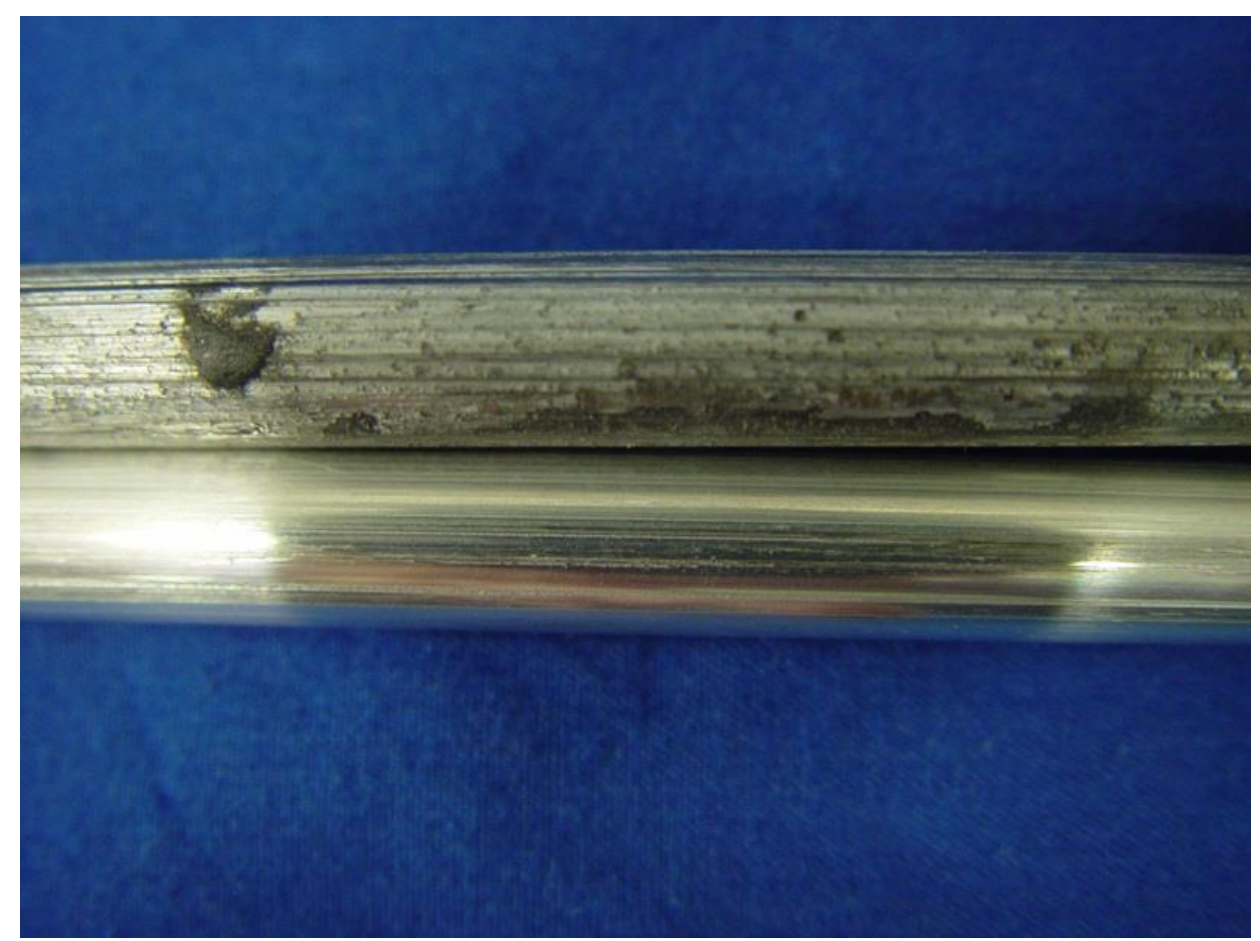

Figure 3.3. Extrusion Surface Finishes on AA6061 using Dag (top) and Filled Grease (bottom) Lubricants

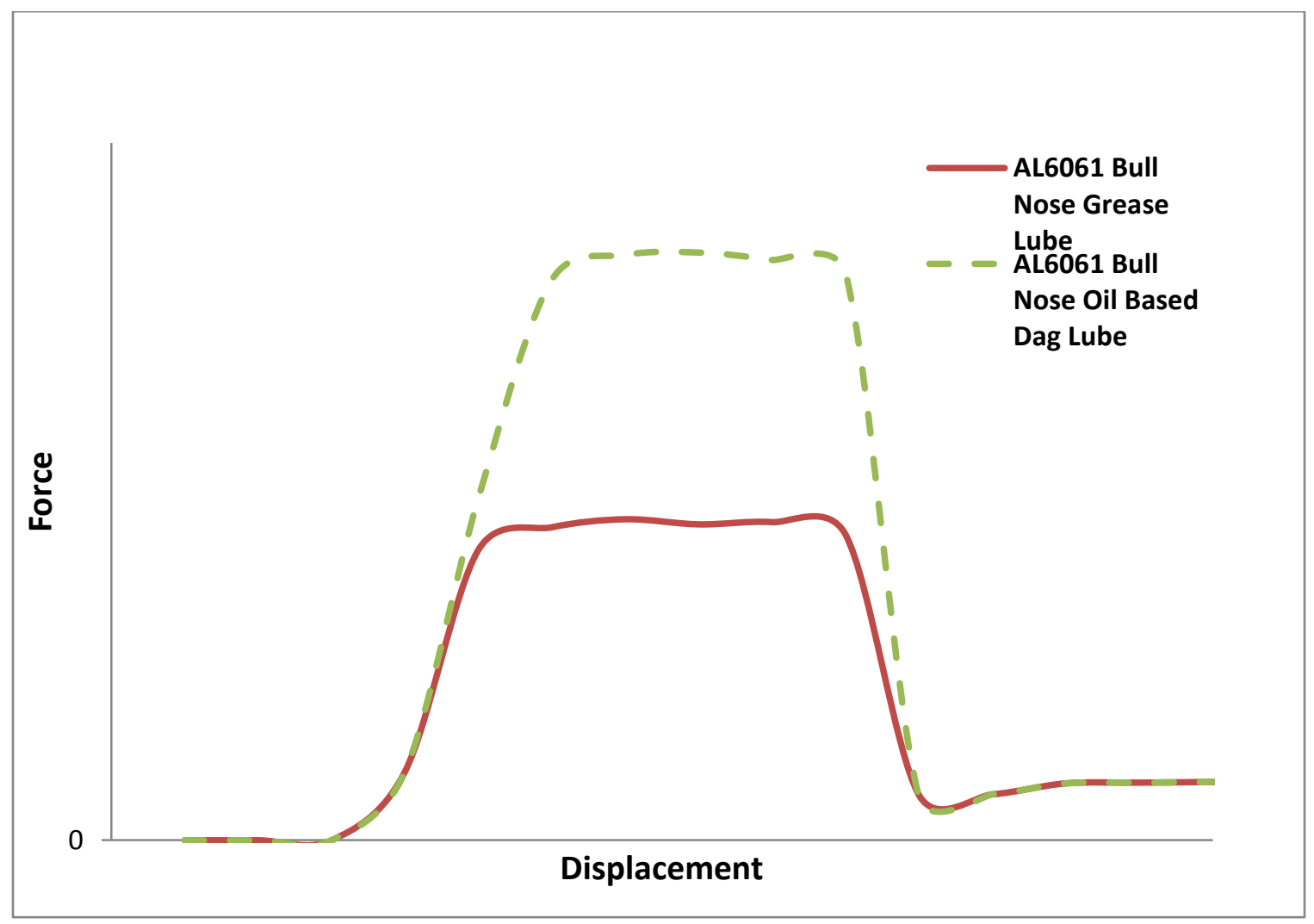

Figure 3.4. Load and Displacement Curves for AA6061 Extruded with Filled-Grease and Dag Lubricants 


\subsection{Development of the Canned Extrusion Process}

In order to make sure the interface between the $\mathrm{Zr}$ and the $\mathrm{U}-10 \mathrm{Mo}$ is clean, an outer can that acts as a hermetic barrier is required to prevent oxidation of the $\mathrm{U}-10 \mathrm{Mo}$ and $\mathrm{Zr}$ during billet preheat and extrusion. The challenge for canned extrusion is the selection of the can materials. The can must be weldable for sealing, oxidation resistant and ideally has a flow stress that matches the material to be extruded. Alternatively, the outer can may be used to provide a softer outer layer having lower flow stress and low reactivity with the steel extrusion tooling. Copper canning of uranium extrusions was a standard practice for extruding N-Reactor fuels (11). This canning process resulted in lower extrusion forces and less oxidation of the DU billet. For simplicity in the initial trials, it was decided that canning of the billet with copper-based alloys using the high-temperature grease lubricant should be the focus of further extrusion process development.

To validate the performance of the extrusion press at near-maximum stress levels, billets of 304SS were machined and fitted to the copper-based alloys and extruded at temperatures up to $850^{\circ} \mathrm{C}$ using a high-temperature filled-grease lubricant. Although generating significantly higher extrusion forces than AA6061, the canned 304SS was extruded successfully at loads sufficiently below the extrusion press design limits. Figure 3.5 shows a cross-section and longitudinal section of the copper-alloy/304SS extrusion, which displays uniform thickness and a uniform interface between the outer alloy and 304SS. The plots of the un-canned and canned 304SS billet extrusion load as a function of time are shown in Figure 3.6. In this case the 304SS was extruded at a temperature expected to match the flow stress of the U-Mo based on hot compression testing performed in a prior GTRI study (12). Interestingly, the extrusion of the 304SS was also carried out without the can at a ratio of 3:1 and the force was as high as that for the canned 304SS at a ratio of 6:1, indicating that the can was reducing the force needed for extrusion.

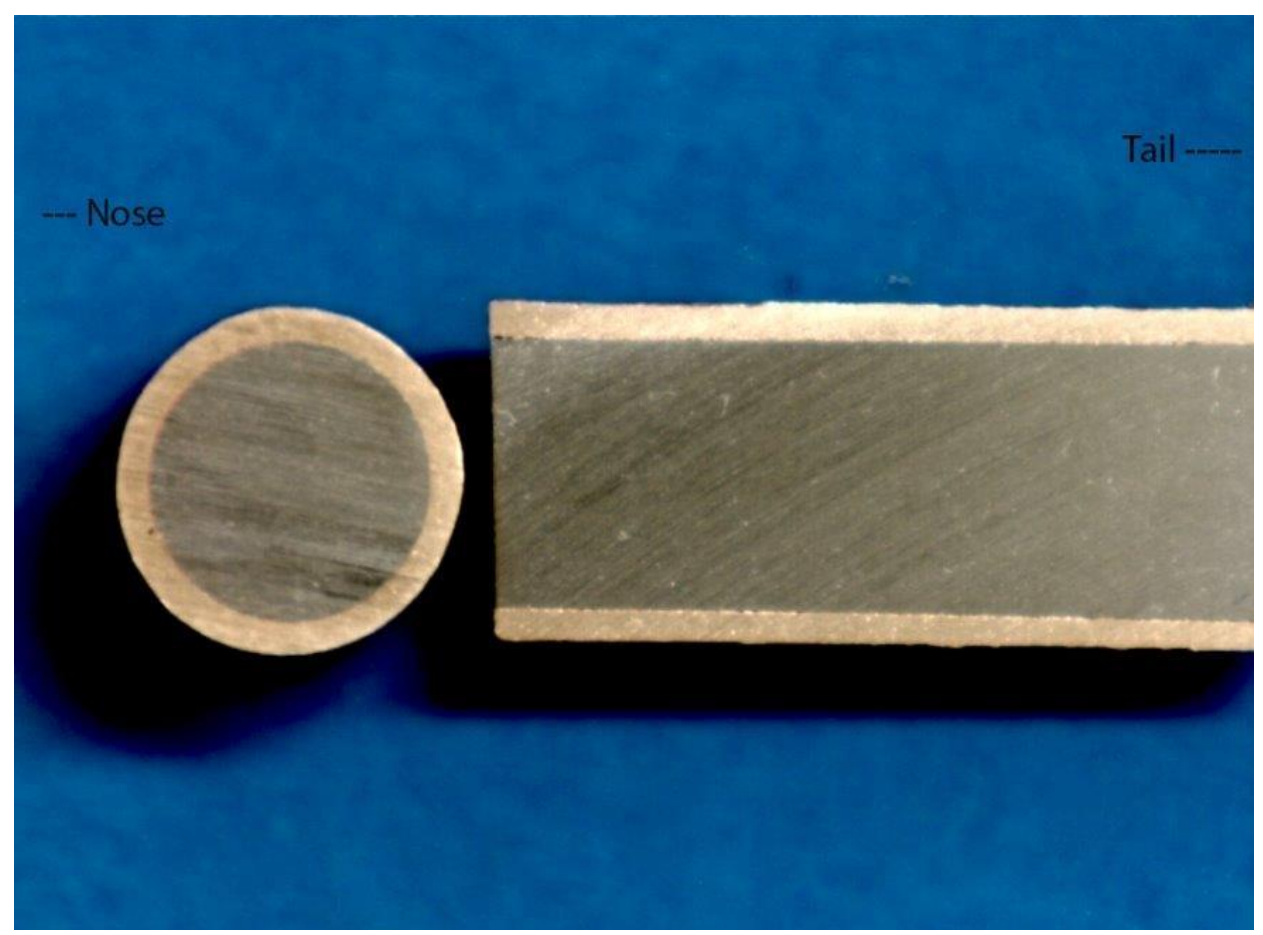

Figure 3.5. Cross-Section of the Extruded 304SS and Cu-Based Alloy Can 


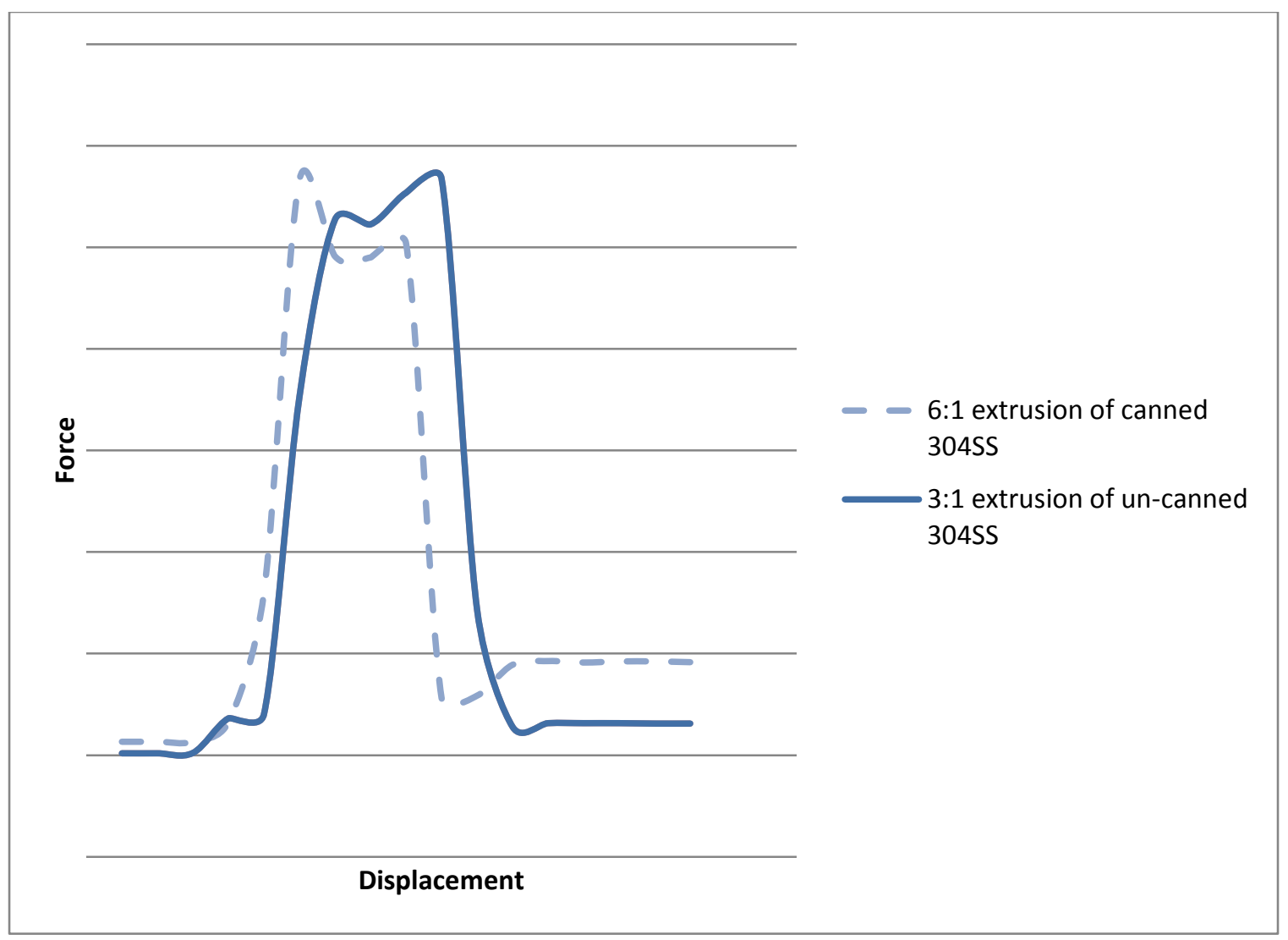

Figure 3.6. Force versus Displacement Curve for the Extrusion of 304 Stainless, Canned and Uncanned. The uncanned extrusion was near the force limit of the extrusion press at a ratio of 3:1 and would not have extruded at 6:1, indicating the lower forces need for canned extrusion.

\subsection{DU-10Mo Extrusion Demonstration}

DU-10Mo billets were machined from a casting available for use in the project as shown in Figure 3.7. A casting was available that had sufficient dimensions to obtain 12 billets. All machining was performed by Energy Solutions - Manufacturing Sciences Corporation (Oak Ridge, TN) under contract to PNNL. The chemistry of the casting was nominally 10 weight percent Mo and contained the elements $\mathrm{Si}$, $\mathrm{Fe}$ and $\mathrm{C}$ in 660, 265 and $370 \mathrm{ppm}$, respectively as shown in Table 3.1. Negligible variation in chemistry from the top and bottom of the casting was observed. It has been reported that Fe and Si increase the hot strength in alpha uranium and this composition would be expected to require a very high extrusion force (13). Although the composition of this casting may deviate from that desired for the GTRI USHPRR fuel, the casting is adequate to demonstrate processing of the U-10Mo into complex shapes. In fact, the alloy likely will provide a desirable conservatism in the results because a non-typical casting technique was used and the production HPRR castings are not likely to have this Si level. 


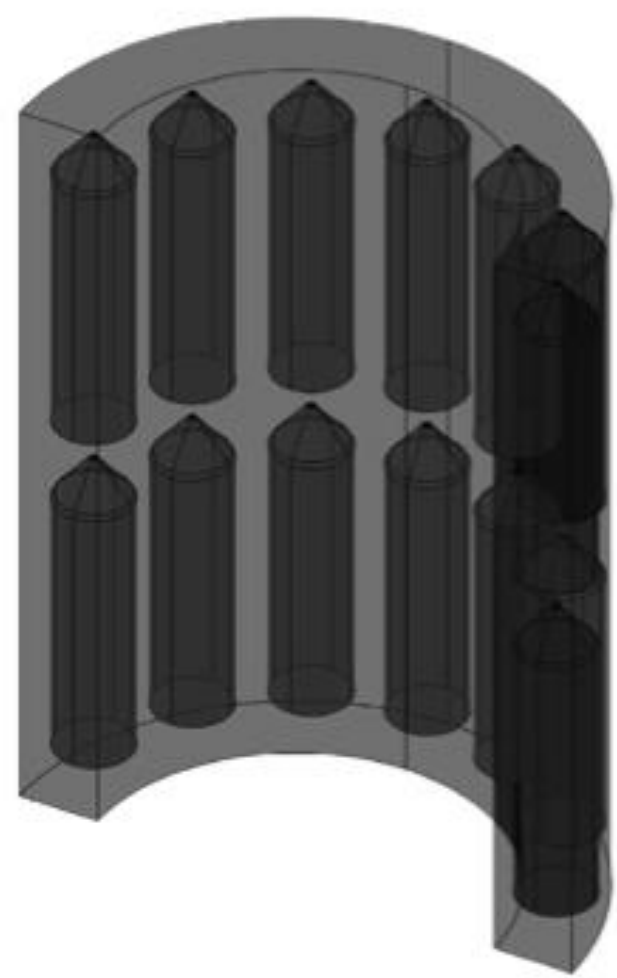

Figure 3.7. DU-10Mo Casting from Which the Extrusion Billets were Machined. The images of the billets show their relative positions in the casting.

Table 3.1. As-Cast Chemistry for the Log Casting from Which the Extrusion Billets were Machined

\begin{tabular}{lccccccc}
\hline & $\begin{array}{c}\text { Molybdenum } \\
\text { Weight Percent }\end{array}$ & $\begin{array}{c}\text { Carbon } \\
\mathrm{ppm}\end{array}$ & $\begin{array}{c}\text { Silicon } \\
\mathrm{ppm}\end{array}$ & $\begin{array}{c}\text { Iron } \\
\mathrm{ppm}\end{array}$ & \multicolumn{2}{c}{ Total Others } & Uranium \\
$\mathrm{ppm}$ & & \\
\hline Top & 10.4 & 370 & 650 & 250 & $<100$ & Balance \\
Bottom & 10.3 & 370 & 670 & 280 & $<100$ & Balance \\
\hline
\end{tabular}

After machining, the DU-10Mo billets looked like the billet shown on the right side of Figure 3.8. No gross flaws were found in any of the billets and the surfaces after machining were smooth and on the order of 16 microinches of roughness. Initially, one DU-10Mo extrusion billet was canned using the can shown on the left side of Figure 3.8. Because there was no attempt to bond in the initial extrusion, the can lid was peened to hold the lid in place rather than welded. 


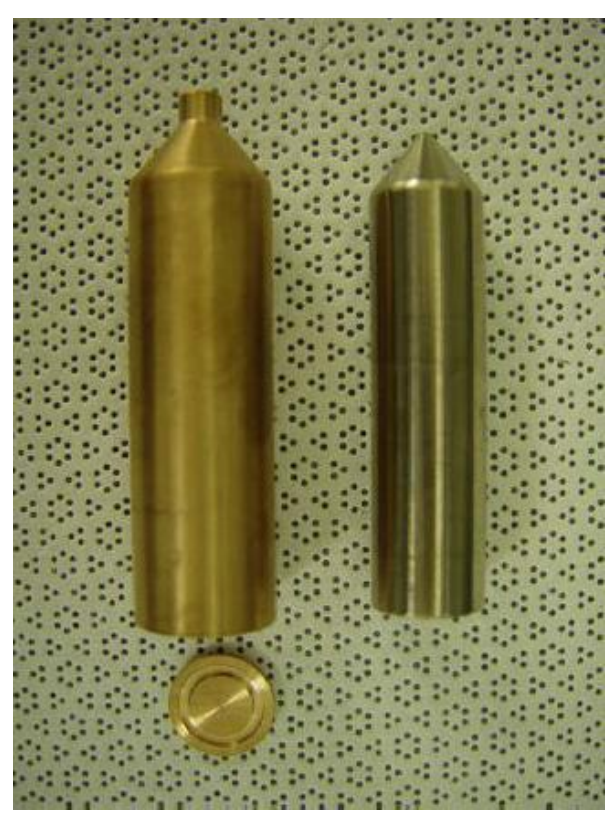

Figure 3.8. Cu-based Alloy Can and U-10Mo Billet Prior to Assembly and Extrusion

The billet was extruded in the gamma phase field (above $770^{\circ} \mathrm{C}$ ) at a ratio of approximately $6: 1 \mathrm{using}$ the previously developed combination of copper can and grease lubrication. The extrusion was approximately 14" long and appeared sound in that there was no obvious tearing or breaching of the can, as shown by Figure 3.9.

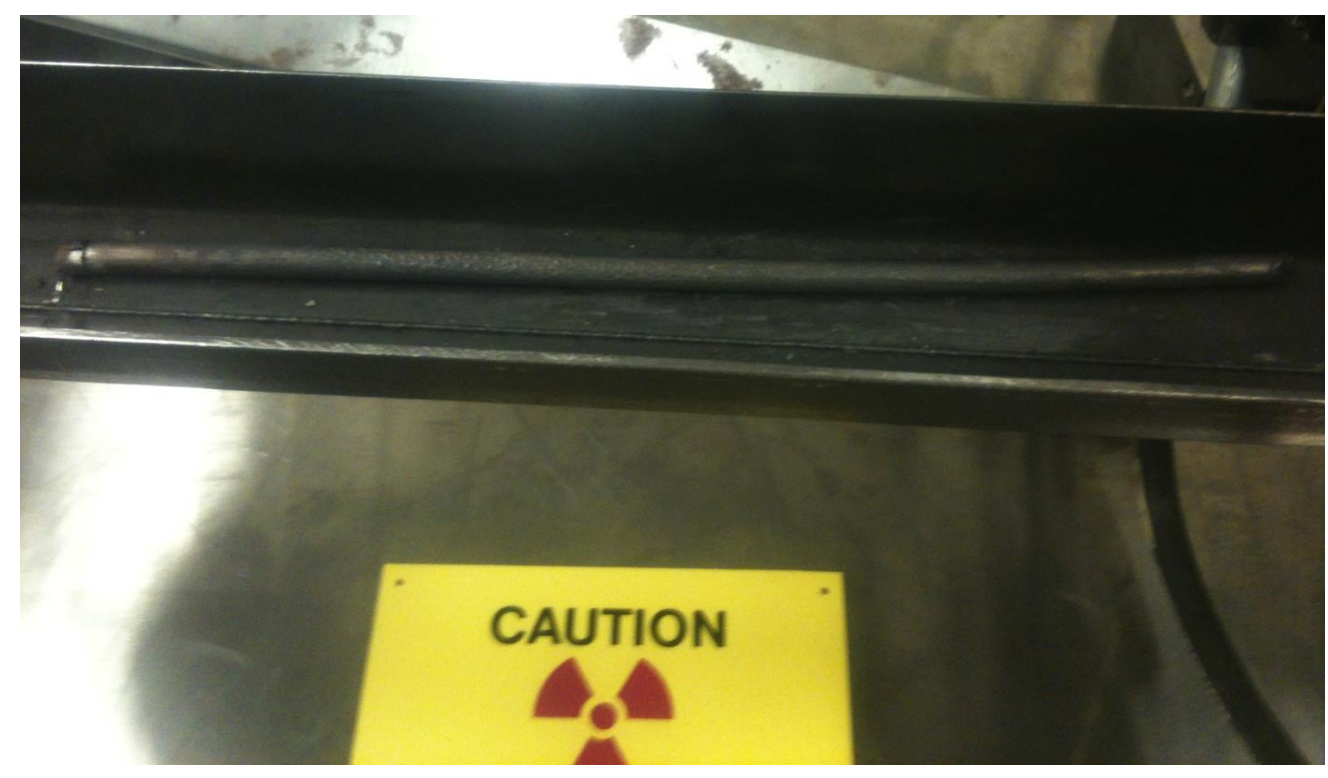

Figure 3.9. DU-10Mo Extrusion Cooling in the Runout Tray after Extrusion

The extrusion force for the DU-10Mo is given in Figure 3.10 and was nearly identical to the force measured in the extrusion of canned 304SS surrogate material. The force was within the operating limits of the press and showed an initial high upset force followed by a slightly increasing running force. 


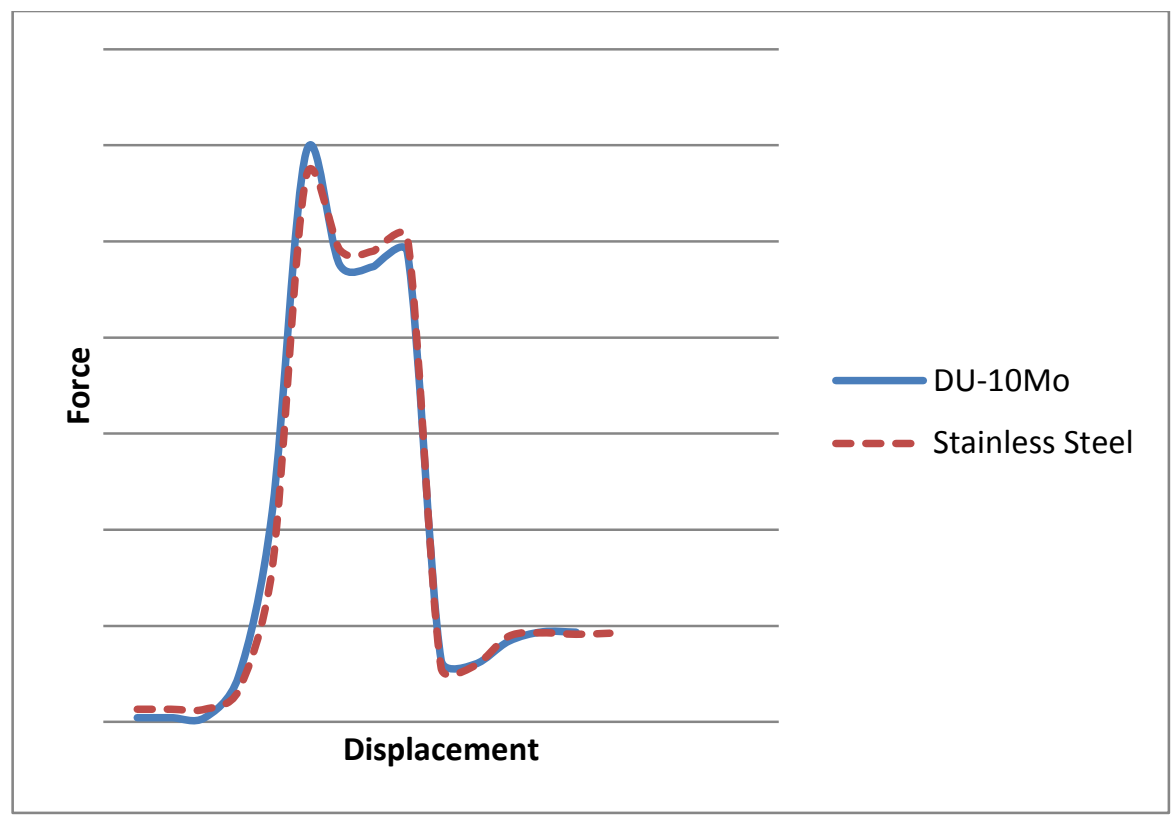

Figure 3.10. Force-Displacement Diagram for the U-10Mo and canned 6:1 Stainless Steel Extrusion Showing a Relatively High Upset Force Followed by a Relatively Constant Running Force

Microstructural characterization was performed on the casting from which the billets were machined and on the extruded rods. The as-cast samples were cut along the transverse direction for microstructural characterization and samples were obtained from the top, middle and bottom sections of the casting. The as-extruded rods were cut along the extrusion axis (longitudinal section) for microstructural characterization. Samples from the front, middle and tail of the extruded rods were used for the microstructural characterization.

For the microstructural analysis, samples were cold mounted in an epoxy resin. The mounted samples were successively polished to 600 grit with SiC polishing papers and were further polished using $6 \mu \mathrm{m}$ and $1 \mu \mathrm{m}$ diamond slurries, followed by a final colloidal silica polish. Upon polishing, the samples were gold coated for scanning electron microscopy (SEM) analysis. The detailed technique used to prepare the samples for characterization can be found in Reference (12). Microstructural characterization was performed using an optical microscope as well as using a JEOL JSM-7600F SEM equipped with an Oxford Instruments X-Max 80 energy dispersive x-ray spectroscopy (EDS) detector. The EDS analysis was performed using the INCA Microanalysis Suite software, version 4.15.

Figure 3.11a is the backscattered SEM image of the as-cast/as-received sample taken from the middle section of the billet. The microstructure of the bottom and top regions (not shown) closely resembled that of the middle section. It was observed that the grain size of the as-cast sample ranged between 300 and $500 \mu \mathrm{m}$ and was bimodal in distribution. The grain boundaries were decorated by Chinese-script molybdenum silicide and plate/needle shaped uranium carbide as shown in Figure 3.11b. Based on the backscattered electron (BSE) image (Z-contrast) and subsequent EDS analysis, given in Figure 3.12, microsegregation of molybdenum was observed within the grains. Based on the EDS analysis, it was determined that the difference in the molybdenum concentration within the grains and along the grain boundaries was approximately $2-3$ weight percent, i.e., the centers of the grains were rich in molybdenum. 


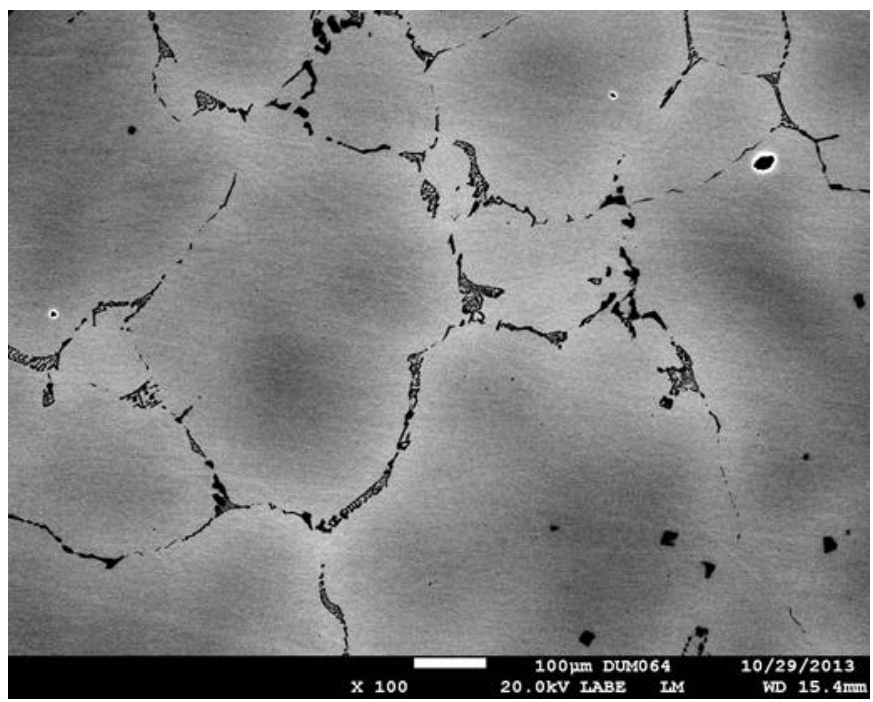

(a)

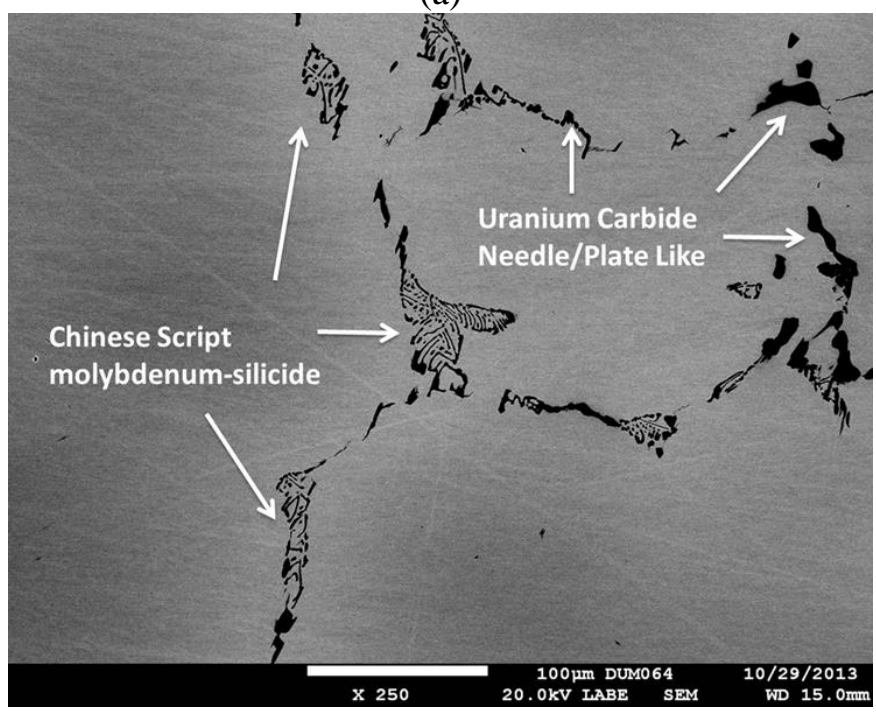

(b)

Figure 3.11. Backscattered SEM Image of the Transverse Section of the Middle Region of the As-Cast Billets: (a) Low Magnification Image at $100 \times$ and (b) High Magnification Image Showing the Chinese-Script Structure of the Molybdenum Silicide and the Plate/Needle Structure of the Uranium Carbides 


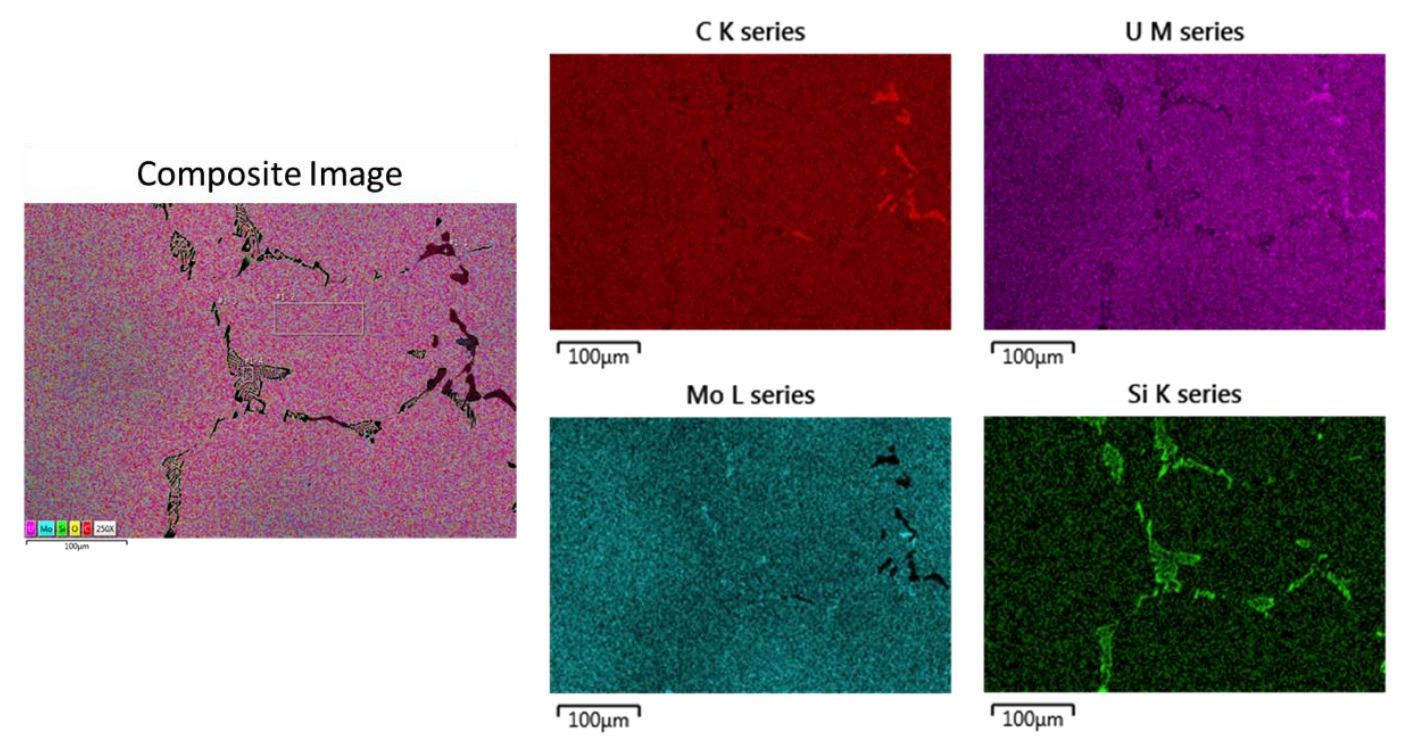

Figure 3.12.EDS Map of the As-Cast Sample Indicating the Presence of Silicon and Molybdenum in the Script Regions (gray) and Uranium and Carbon in the Plate/Needle Regions (black)

Figure 3.13a and $\mathrm{b}$ are macro-images of the transverse and longitudinal sections of extruded billets from near the middle of the extrusion. The interface between the cladding and the U-10Mo exhibited many asperities, indicating that the surface of the U-10Mo was likely to be very rough. Otherwise, no gross extrusion defects such as hot tearing or central burst were observed and the extrusion was very sound and uniform from the nose to the tail. The average can wall thickness (other than the previously mentioned asperities) did not vary, indicating that the extrusion was not tapered and the extrusion conditions were uniform from nose to tail.

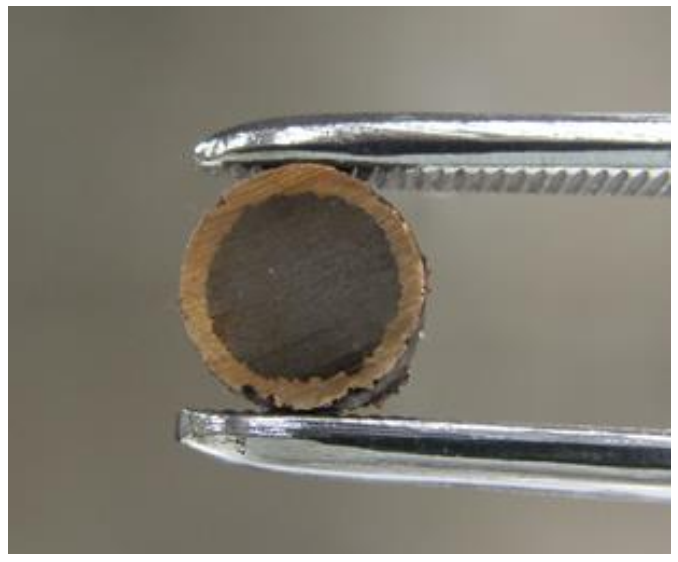

(a)

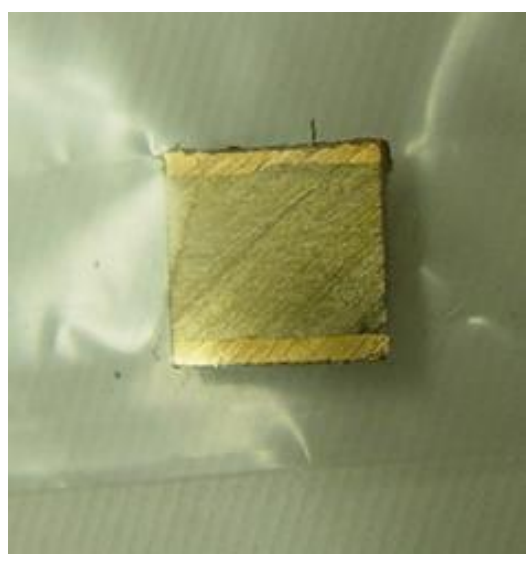

(b)

Figure 3.13. Macro-Images of the Extruded DU-10Mo Rod: Transverse (a) and Longitudinal (b)

Figure 3.14 is a low magnification BSE-SEM image (montage) of the nose of the extrusion in the longitudinal view. The microstructure is typical of an as-extruded sample from a non-homogenized casting and exhibited a typical bamboo-tree structure. It was observed that the grains elongated along the extrusion direction. The equiaxed grains that were approximately $500 \mu \mathrm{m}$ in the as-cast structure increased to more than $800 \mu \mathrm{m}$ along the longitudinal direction and were approximately $250 \mu \mathrm{m}$ in the 
transverse direction. The smaller grains elongated to approximately $500 \mu \mathrm{m}$ along the extrusion axis whereas the grain size was less than $50 \mu \mathrm{m}$ perpendicular to it. The segregation of the molybdenum within the grains was retained and appeared to have formed bands. The silicides and carbides were present at the grain boundaries. It was observed that the density of the intermetallics and carbides was higher at the narrow ends of the coarse grains and fairly uniform around the finer grains, as shown in Figure 3.14. There was no evidence of (macro) porosity across the entire cross-section.

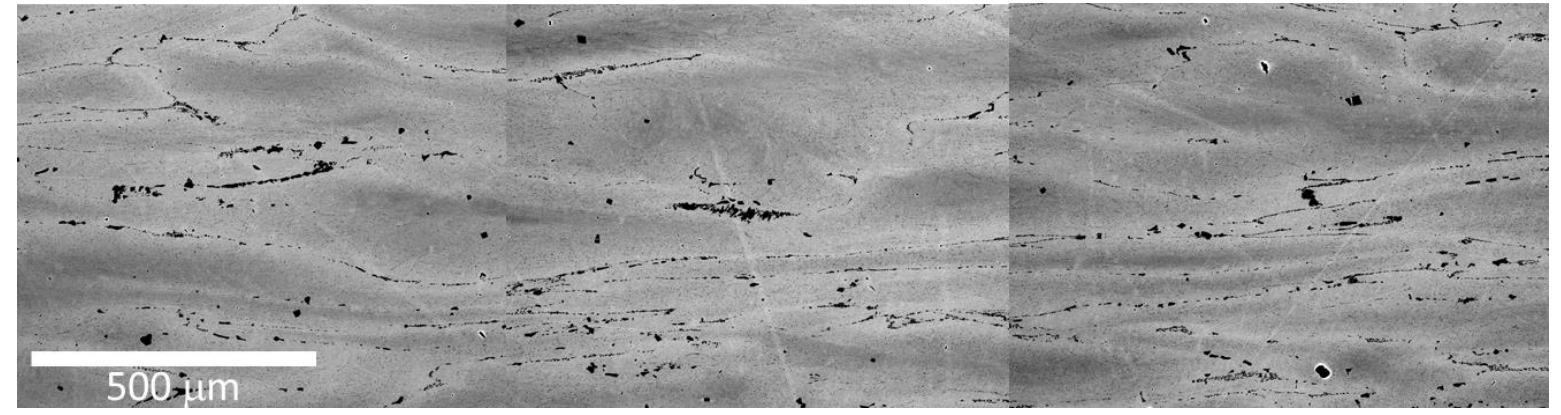

Figure 3.14.Low Magnification BSE-SEM Montage of the Tip of an Extrusion along the Longitudinal Direction of the Extrusion

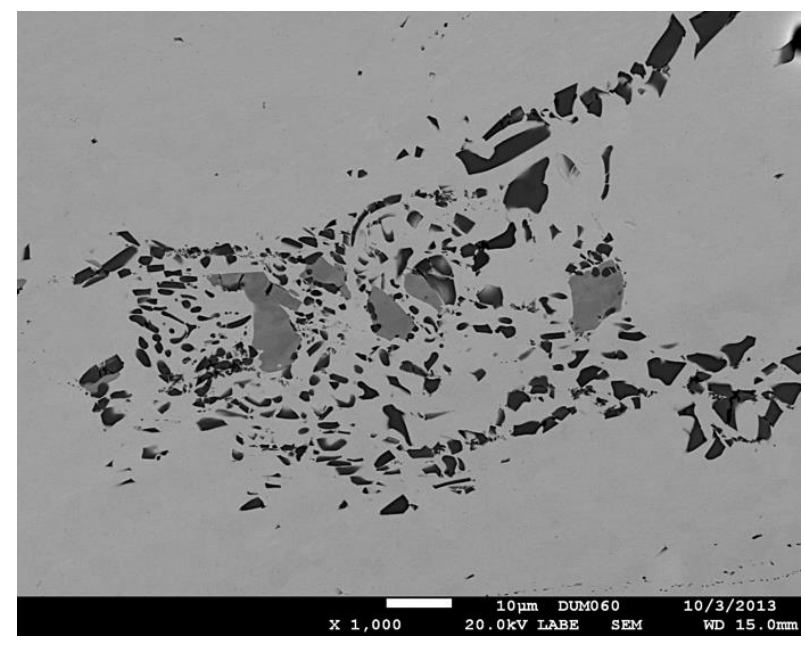

(a)

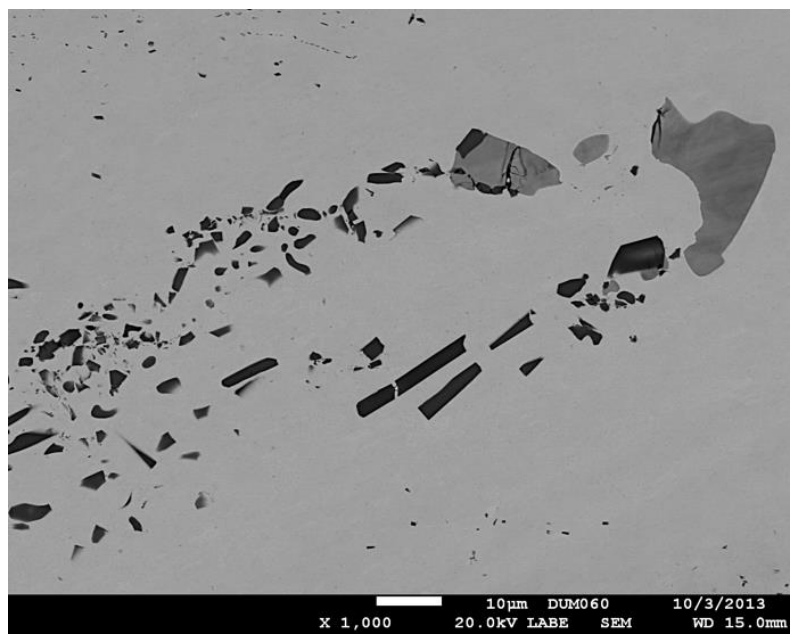

(b)

Figure 3.15. High Magnification BSE-SEM Images of the Region of Microstructure Showing the Effect of the Extrusion Strain on the Particle Fracture

Figure 3.15a and $\mathrm{b}$ are high resolution BSE-SEM images that show the effect of extrusion on the intermetallics and carbides, which were located at the grain boundaries in the as-cast structure. Figure 3.16 is the elemental EDS map of Figure 3.15 Based on the distribution of the silicides and carbides, as shown in Figure 3.15, it was concluded that the extrusion process caused the Chinese-script molybdenum silicides (black) and plate/needle-like carbides (gray) to be completely broken down and form isolated clusters along the grain boundaries. These particles appeared to have fractured into two or more parts and in certain cases voids were visible within the interparticle regions. The carbides in Figure 3.15a that had a lower aspect ratio seemed to have remained intact during extrusion and were not fractured, as indicated by the lack of porosity around the particles. Particle sizes of the intermetallics varied from 1-6 $\mu \mathrm{m}$ in length and $0.5-2 \mu \mathrm{m}$ in width. 


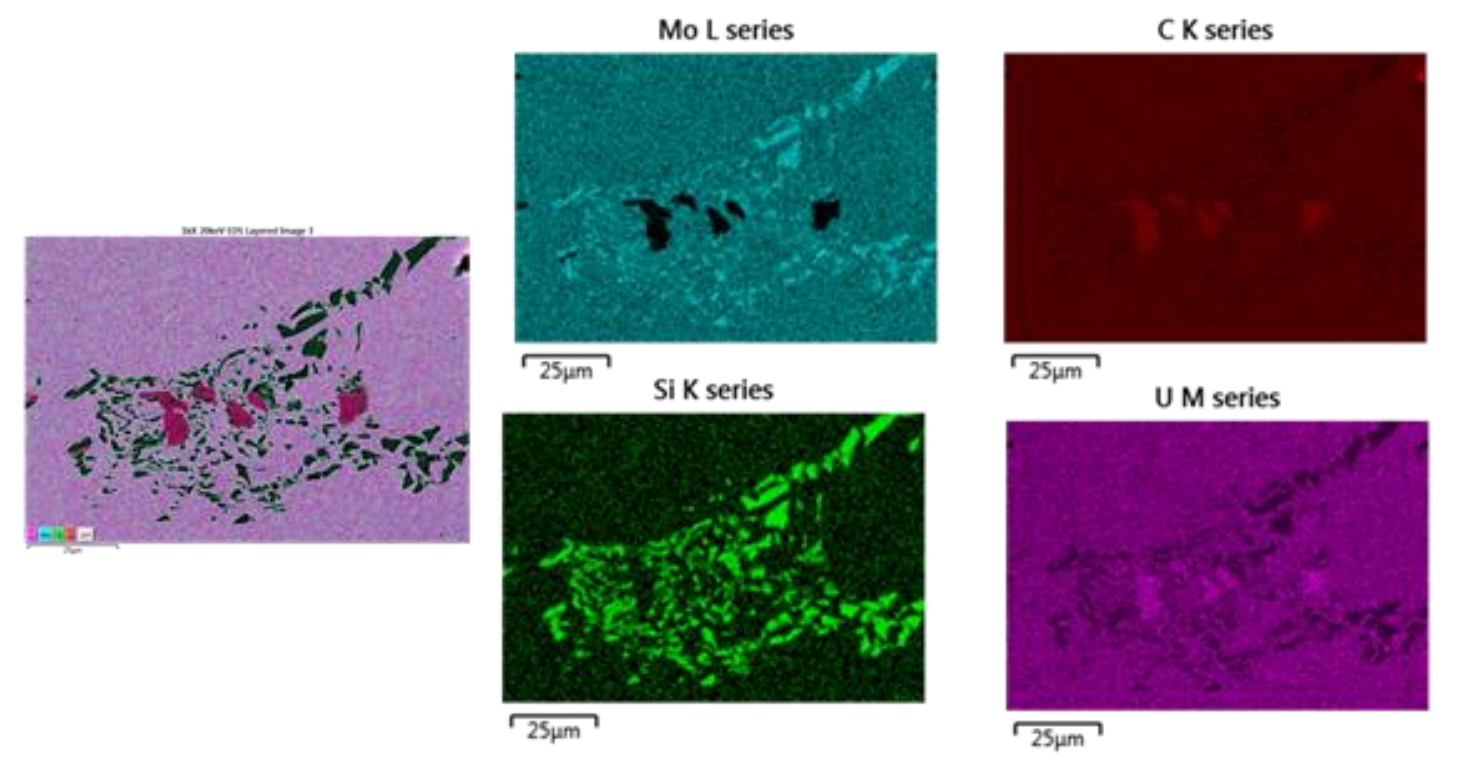

Figure 3.16. Elemental EDS Map of the As-Extruded Intermetallics and Carbides

The extrusion appeared to reduce the cast structure uniformly form nose to tail, indicating little change in the condition of the extrusion from start to finish. Figure 3.17 shows an example of the uniformity of the structure from start to finish, indicating a relatively homogeneous reduction occured during extrusion.

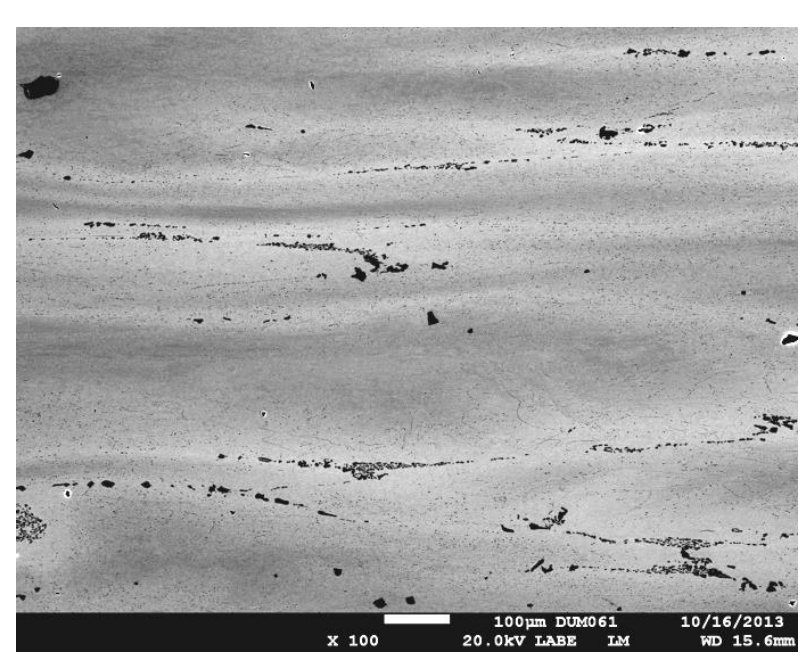

(a)

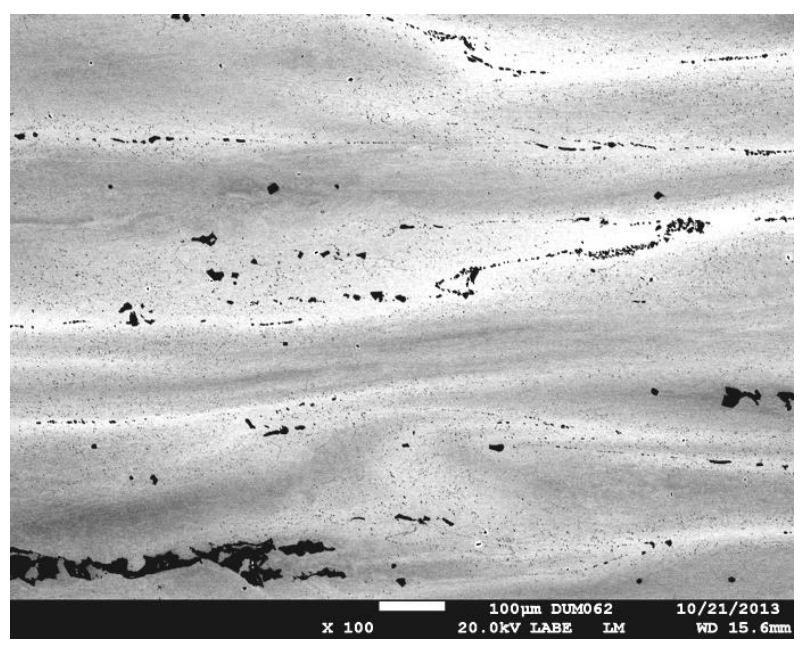

(b)

Figure 3.17. Low Magnification BSE-SEM Images of the Extrusion at the Middle (a) and Tail (b) of the Sample along the Extrusion Direction

As expected from the asperities shown in the transverse cross-section of the extrusion in Figure 3.13a, the surface of the U-10Mo was very rough after removal of the can. The roughness was not measured but can be observed visually in Figure 3.18, which shows the inside surface of the can and the outside surface of the U-10Mo extrusion. 


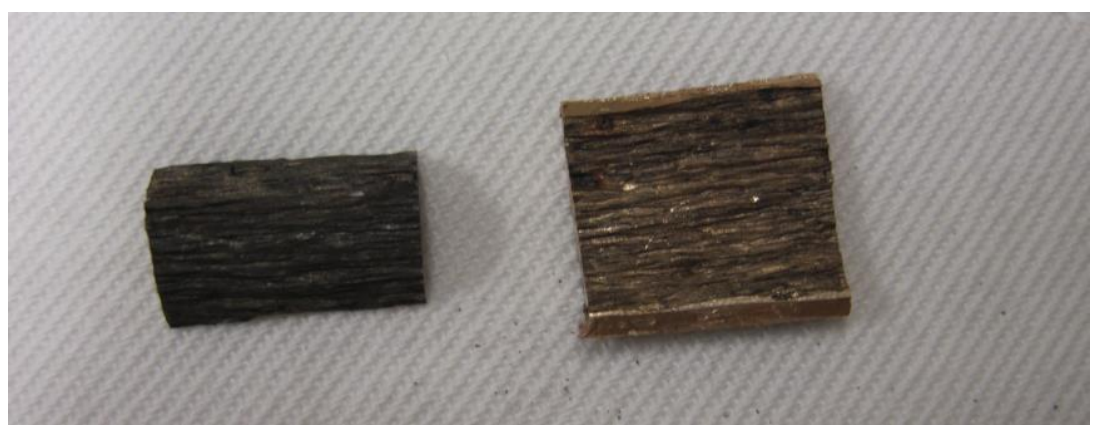

Figure 3.18. The DU-10Mo Extrusion (left) and the Peeled-Off Can (right) Showing the Rough Surfaces

\subsection{Complex Shape Development}

The primary advantage of the co-extrusion process is the ability to clad the U-10Mo in shapes other than flat plates, as will be done with the baseline co-rolling process. During FY13, extrusion dies were designed and fabricated to produce a Zr-clad "airfoil shape" of the HFIR fuel. Given the forces required for U-10 Mo extrusion and the dimensional tolerances of the HFIR fuel, it would be impractical to extrude to the final size. Therefore, the HFIR fuel shape must be made by combination of hot extrusion for bonding and cold rolling to final shape.

For the studies in this project, a profile of a sub-sized "HFIR-like" fuel was designed to match the maximum width of the current PNNL extrusion tooling (approximately 0.8 inches or $22 \mathrm{~mm}$ ). This "HFIR" fuel and an extrusion die were designed by back-calculating the profile from the HFIR profile given in Figure 2.2. This back-calculation was made by assuming that the U-10Mo can be cold rolled $15 \%$ in a single pass and then increasing the cross-sectional area of the profile in multiple rolling steps by $15 \%$. It is important to note that just "opening or closing" the rolls will not result in uniform reduction and that each pass must have a unique profile as is illustrated by Figure 3.19. If a single profile were to be used and the rolls opened or closed, the strain across the width of the fuel would not be uniform and the foil shape would be heavily bowed. Therefore, each pass was calculated to produce a uniform strain across the fuel width. In the resulting passes, shown in Figure 3.19, Pass 1 is a 15\% reduction from the 3:1 extrusion, Pass 2 is a 15\% reduction from Pass 1, Pass 3 is a 15\% reduction from Pass 2, and so on until the final pass, Pass 6 , achieves the final fuel dimension. 


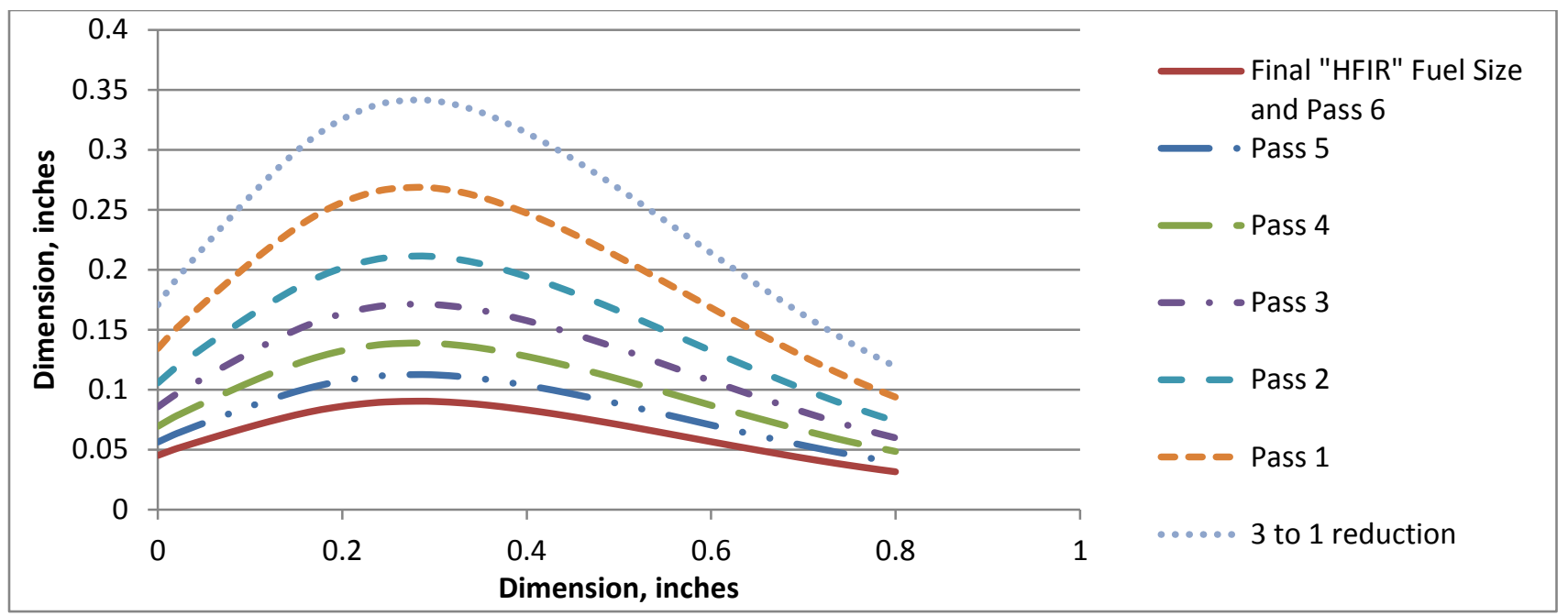

Figure 3.19. Roll Groove Profiles for the Roll Pockets Needed to Roll a Complex Shaped Extrusion to the HFIR Profile Using a Reduction Ratio of 3:1

Another challenge associated with the complex profile is the impact of the increased surface area when compared with a circular rod of similar cross-sectional area. This increased surface area may increase the contribution of friction and raise the extrusion force substantially. In order to accommodate this unknown force increase, the roll passes have been designed to accommodate a much lower extrusion force at a 3:1 reduction ratio. From the first DU-10Mo extrusion, the capability was demonstrated to safely extrude a rod at a reduction ratio of $6: 1$ and it is conservative to assume that the reduction may be reduced by $50 \%$ due to the increased surface area. In addition to the 3:1 extrusion ratio, the roll pockets have been designed to accept an extrusion at 4.5:1 (in Pass 3) and 6:1 (in Pass 5). Therefore, if the extrusion at 3:1 has a lower-than-expected force, a new die can be fabricated and the U-10Mo can be extruded at $4.5: 1$ or $6: 1$ and use the same reduction schedule built into the roll pockets.

The next issue with shaped components is the extrusion process along with the expected straightness and forces. To minimize force and increase the probability of a straight extrusion, the concept of streamline extrusion was used to design the extrusion dies (14). The as-designed die is shown in Figure 3.20 and describes how the material will flow through a curved surface rather than a straight surface. The purpose of the curved flow line of the streamlined die is to minimize redundant work entailed in flat and conical dies while making the strain across the cross-section of the extrusion as it "arrives" at the size point as uniform as possible. If the material arrives at the size point of the die with uniform strain, the extrusion will be straight; if the strain is not uniform the extrusion may be very bowed and difficult to straighten prior to rolling. Ideal streamline flow cannot be achieved because it would require an infinitely long die; however, the design approach is certainly far better than a conical or straight die face. 


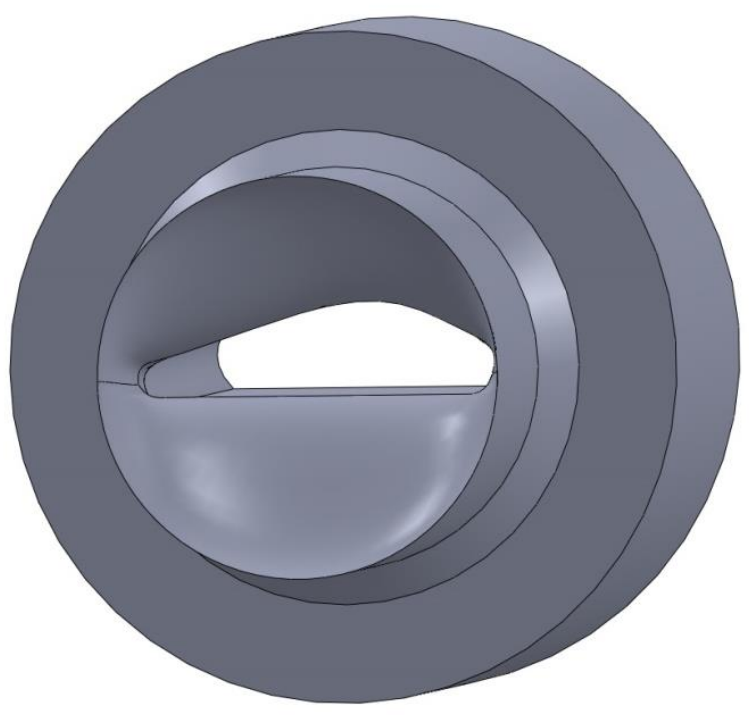

Figure 3.20. Streamlined Extrusion Die for the Shaped Co-Extrusion to be Rolled to the HFIR Profile

Although it is relatively simple to calculate the profile of the roll for each pass, the depth of the groove in the roll creates a challenge due to the relative mismatch of surface velocities at the deepest and shallowest locations of the groove. This velocity mismatch, called slip factor, can result in surface tearing, non-uniform residual stress (lack of straightness) and, in severe cases, fracture of the part being rolled. In order to accommodate the slip factor for the grooves, portions of the groove are ground into both the top and bottom roll. The separation of the grooves into portions minimizes the depth and, thus the slip factor mismatch, but also prevents lateral spread of the rolled material and produces better control over dimensions. Engineered drawings of the grooves designed for the "HFIR" fuel size are given in Figure 3.21. The rolls will be ground to meet the dimensions of this drawing. 


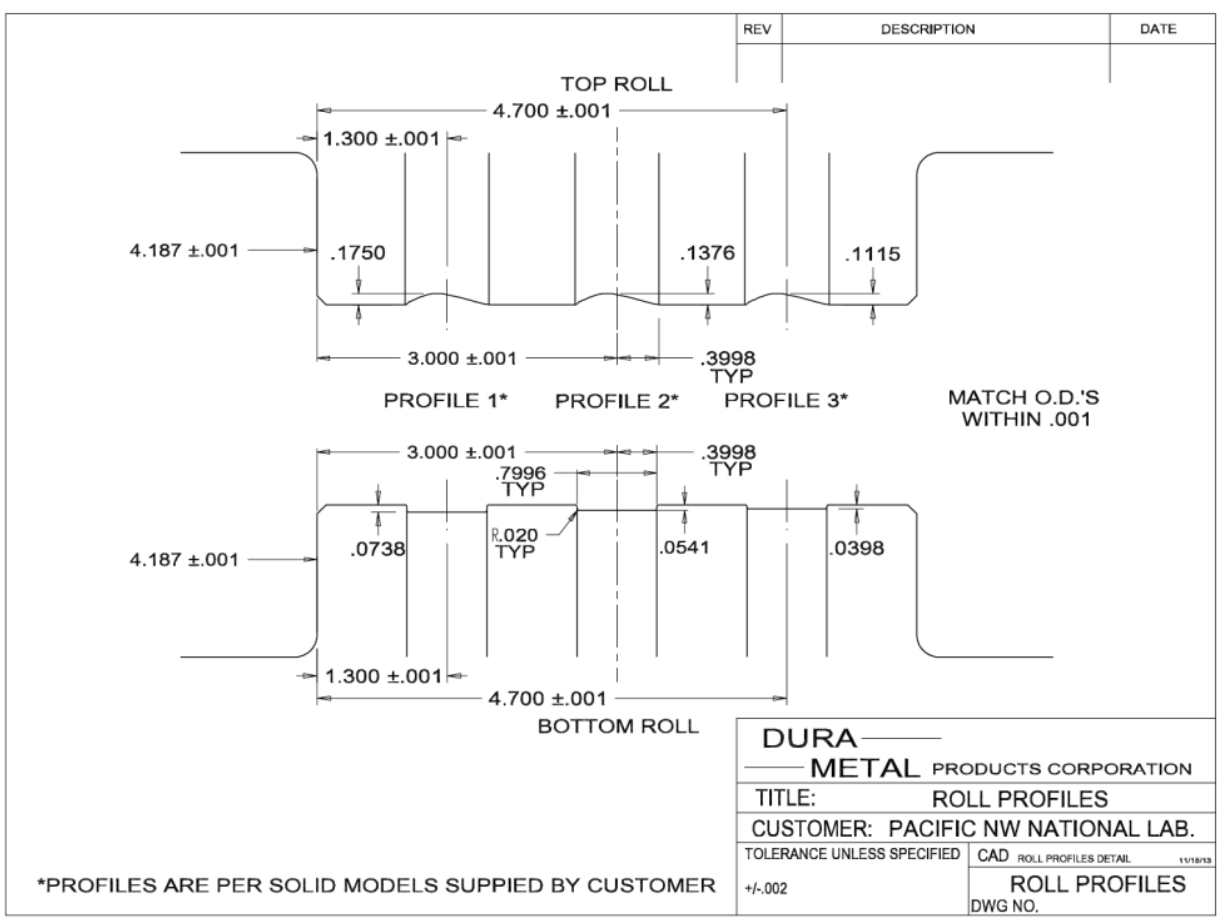

Figure 3.21. Engineered Drawings of the Roll Pockets for Rolling the Shaped Extrusion to the HFIR Profile 


\subsection{Discussion}

The approach to the development of a co-extruded complex-shaped fuel has been described and an extrusion of DU-10Mo was made. The extrusion made during FY13 was valuable in process design because the extrusion forces for the 6:1 extrusion were high and approached the limit for high volume commercial production. It is important to assess at an early stage the viability of the process to meet the production demands. Based on the experience of the first extrusion, it is likely that a billet $75 \mathrm{~mm}$ in diameter and approximately $300 \mathrm{~mm}$ in length can be extruded to a profile that can be rolled to the HFIR shape. Such a billet would weigh approximately $26 \mathrm{~kg}$ and would produce an extrusion from $900 \mathrm{~mm}$ to $1800 \mathrm{~mm}$ in length. This extrusion would produce approximately 30 HFIR fuel foils and the extrusion cycle time for each extrusion would be about 2 minutes. Even at modest productivity, the co-extrusion process could meet the approximately 3,300-piece fuel plate demand of HFIR in a few days of production (10). In addition, the canning process would not require the extensive fit-up of the picture frame and would likely be a simpler process. Therefore from the initial successful extrusion and a simple calculation, it seems viable to consider co-extrusion as a method for production of the HFIR fuel, assuming the technical challenges can be overcome.

The technical challenges of the co-extrusion process are being addressed now that a viable extrusion system has been built and validated. The likely challenges will be the development of a better surface finish of the U-10Mo to produce uniform $\mathrm{Zr}$ thickness and the ability of the $\mathrm{Zr}$-clad extrusion to be rolled while maintaining $\mathrm{Zr}$ integrity. Regarding the first point, this roughness was not unexpected and, in past experience, has been addressed by billet chemistry, heat treatment and thermomechanical processing; in fact, in N-Reactor fuels production the variation in clad thickness was a function of billet microstructure, not of process parameters (6). In order to start to address the roughness issue, the next extrusion will be homogenized and sleeved in $\mathrm{Zr}$ prior to extrusion and then canned in a copper-based alloy. The homogenization will improve the uniformity of strength by eliminating the hard and soft bands of low and high Mo content, reducing the bamboo structure, and the $\mathrm{Zr}$ sleeve will be stronger than the can and should prevent the flow of the U-10Mo into the soft can.

The second technical challenge associated with the rolling of the Zr-clad U-10Mo while maintaining $\mathrm{Zr}$ integrity is a difficult step to predict. However, the baseline process for the fuel foil production uses cold reductions and does not appear to result in unbonding (15). It is reasonable to assume that the shaped rolling processing would have similar reductions and not cause unbonding.

Although there are limited results, it seems reasonable to assume that the co-extrusion cold rolling process should be viable as a method to meet the quality and productivity demands of fuel fabrication for the HFIR. Co-extrusion is not a new process, so many of the technical challenges are only new to the U$10 \mathrm{Mo} / \mathrm{Zr}$ co-extrusion. 


\subsection{Summary}

A process path for the production of the HFIR shaped fuel has been identified using co-extrusion for bonding $\mathrm{Zr}$ to U-10Mo and cold shape rolling to achieve final complex shape dimensions. The process appears to be viable to meet USHPRR fuel fabrication demands for production.

An extrusion system was assembled, installed in a radiologically controlled area and used to demonstrate the extrusion of a nominal U-10 Mo billet at a reduction ratio of 6:1.

As expected, the force was very high and approached the design limit of the extrusion press. Higher forces could be used with the PNNL system, but have been restricted to make sure extrusion stresses are commercially practical.

Suitable lubricants for the extrusion of a canned U-10Mo were identified and demonstrated. Glass lubricants proved difficult for the small billets with a high surface-area-to-volume ratio and were not used. To date, no can breaches have occurred and the extrusion system is uncontaminated.

Microstructural examination of the extrusion showed that the extrusion was sound and uniform from nose to tail, but inhomogeneity of the Mo from the as-cast billet remained after extrusion. The extrusion process fractured and homogenized the script structure $\mathrm{Mo}_{2} \mathrm{Si}$ phase but did not fracture the equiaxed carbides.

The surface of the extrusion after can removal was far too rough for the GTRI fuel tolerances, and paths forward have been identified and will be implemented in the FY14 test plan. The rough surfaces will not prevent the ongoing development of the HFIR shape rolling process.

The alloy available for demonstration contained approximately 650, 320 and $260 \mathrm{ppm}$ of $\mathrm{Si}, \mathrm{C}$ and $\mathrm{Fe}$, respectively. The levels of Si and Fe likely contributed to the elevated flow stress and high extrusion forces. This alloy likely will provide a desirable conservatism in the results as the production USHPRR castings are not likely to have Si levels exhibited in this casting and thus these billets.

Extrusion dies based on the principle of streamlined die design have been designed and fabricated for the HFIR shaped extrusion. The extrusion pressure for the U-10Mo was very high and, therefore, the dies designed to produce the HFIR shape were fabricated for ratios of 3:1, 4.5:1 and 6:1. Maximum extrusion ratio for the HFIR shape will be determined in FY14.

A series of roll grooves have been designed to roll the shaped extrusion to the final dimensions of the HFIR fuel. The roll grooves were designed for $15 \%$ reductions and rolling can be done hot or cold and will accept the extruded shapes using either $3: 1,4.5: 1$ or $6: 1$ reductions. 


\subsection{References}

1. Senor DJ and DE Burkes. 2013. Fuel Fabrication Capability Research and Development Plan. Global Threat Reduction Initiative - Convert Program, PNNL-22528, Pacific Northwest National Laboratory, Richland, Washington.

2. Woolstenhulme NE, et al. 2012. Recent Accomplishments in the Irradiation Testing of EngineeringScale Monolithic Fuel Specimens. RERTR 2012 - 34th International Meeting on Reduced Enrichment for research and Test Reactors, Warsaw, Poland.

3. Lewis M, JE Minor and JT Stringer. 1965. Report to Working Committee from Hanford. RL-REA1025, Richland, Washington.

4. Taylor LL. 2000. N Reactor (U-metal) Fuel Characteristics for Disposal and Criticality Analysis, DOE/SNF/REP-056 Rev. 0. Idaho National Engineering and Environmental Laboratory, Idaho Falls, Idaho.

5. Laue, Kurt* and Helmut Stenger**. 1981. Extrusion. (Copyright in English). Published in U.S. by American Society for Metals. *Formerly Director of Vereingte Deutsche Metallwerke, Frankfurt. **Technical Director of Glyco do Brasil Industria Metallurgica, Ltda. Cataguases, Brazil.

6. Lewis M, JE Minor and JT Stringer. 1964. Fuel Development Committee: Annual report from The General Electric Company, Hanford. Hw-83687, Richland, Washington.

7. Burkes DE, et al. 2009. Update on Fresh Fuel Characterization of U-Mo Alloys. INL/CON-0915633, Idaho National Laboratory, Idaho Falls, Idaho.

8. Waldron MB, RC Burnett and SF Pugh. 1955. The mechanical properties of U-Mo alloys. Atomic Energy Research Establishment (AERE), Harwell, UK. PrePrint 115. Nuclear Engineering Science and Congress, p. 630, December 1955.

9. Painter CL, DJ Senor, CJ Gesh, BE Schmitt, CA Lavender, KJ Geelhood, AL Doherty and RP Omberg. 2010. LWR U-Mo Fuel Development Plan. PNNL-19722, Pacific Northwest National Laboratory, Richland, Washington.

10. Per personal communication with DE Burkes, 2013

11. Gerber M.S., MS. 1993. "Characterization of Mixed Wastes Resulting from Fuel Fabrication at the Hanford Site: Use of Historical Data," In: Characterization of Mixed Wastes, p. 549. http://www.wmsym.org/archives/1993/V1/108.pdf

12. Joshi VV, EA Nyberg, CA Lavender, D Paxton, H Garmestani, DE Burkes. 2013.

"Thermomechanical process optimization of U-10 wt\% Mo - Part 1: high-temperature compressive properties and microstructure." Journal of Nuclear Materials, http://dx.doi.org/10.1016/j.jnucmat.2013.10.065.

13. Kaufmann A. et al. 1957. "Uranium Silicon Alloys." Transactions of the AIME, Journal of Metals, January 1957, p. 23-27. http://iweb.tms.org/NM/FrP-NM-0710-5.pdf.

14. Srinivasan R et al. 1990. "Extrusion Through Controlled Strain Rate Dies." J. Mater. Shaping Technolog. (1990) 8:133-141. http://link.springer.com/article/10.1007/BF02833625\#page-1.

15. Moore GA et al. 2009. Monolithic Fuel Fabrication Process Development at the Idaho National Laboratory. INL/CON-09-17298, Idaho National Laboratory, Idaho Falls, Idaho. 


\section{Distribution}

No. of

Copies

1 Department of Energy

National Nuclear Security Administration

Global Threat Reduction Initiative

1000 Independence Ave.

Washington, D.C. 20002-USA

Mr. Christopher Landers

Dr. Natraj Iyer (PDF)

1 Idaho National Laboratory

P.O. Box 1625

Idaho Falls, ID 83415

Mr. Kenneth Rosenberg

Dr. Mitchell Meyer (PDF)

1 Argonne National Laboratory

9700 S. Cass Ave.

Argonne, IL 60439

Dr. John Stevens
No. of

\section{Copies}

6 Local Distribution

Pacific Northwest National Laboratory

D.E. Burkes

K8-34

D.M. Paxton K2-03

M.T. Smith K2-03

C.A. Lavender K2-44

V.V. Joshi

A Soulami 


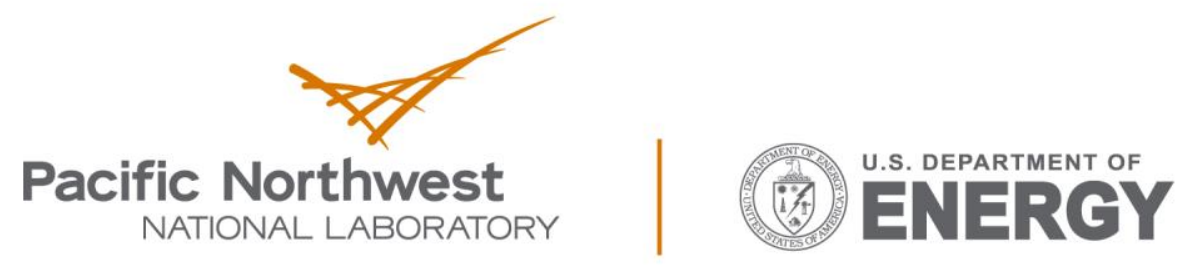

Proudly Operated by Battelle Since 1965

902 Battelle Boulevard

P.O. Box 999

Richland, WA 99352

1-888-375-PNNL (7665)

www.pnnl.gov 